\title{
Analysis of $\mathrm{Gd}_{5}\left(\mathrm{Si}_{2} \mathrm{Ge}_{2}\right)$ Microstructure and Phase Transition
}

\author{
by
}

\section{John Scott Meyers}

\author{
A thesis submitted to the graduate faculty \\ in partial fulfillment of the requirements for the degree of \\ MASTER OF SCIENCE
}

Major: Materials Science and Engineering

Program of Study Committee:

Scott Chumbley, Major Professor

Vitalij K Pecharsky

Gordon J. Miller

Iowa State University

Ames, Iowa 


\section{Graduate College \\ Iowa State University}

This is to certify that the master's thesis of

John Scott Meyers

has met the thesis requirements of Iowa State University

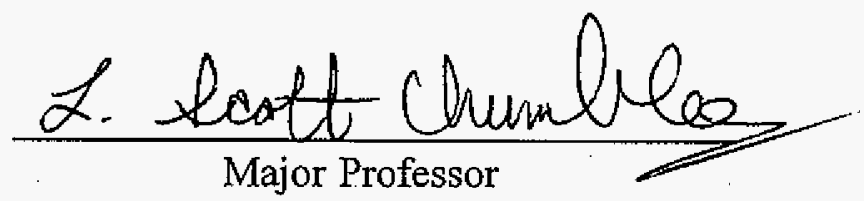

For the Major Program 


\section{Table of Contents}

Chapter 1. Introduction

History

Crystal Structure

$\begin{array}{ll}\text { Chapter 2. SEM Analysis } & 10\end{array}$

Experimental Details $\quad 10$

Results $\quad 11$

Discussion $\quad \cdot 16$

$\begin{array}{ll}\text { Summary and Conclusions } & 19\end{array}$

Chapter 3. A Microstructural Analysis of Twinned B-Gd5Si2Ge2 21

Abstract $\quad 21$

$\begin{array}{ll}\text { References } & 31\end{array}$

Chapter 4. TEM Analysis 32

Experimental Details $\quad 32$

Experimental Results $\quad 33$

Cold Stage Experiments $\quad 40$

Discussion $\quad 42$

Summary and Conclusions $\quad 51$

References ' $\quad 52$

Acknowledgments $\quad 56$ 


\section{Chapter 1. Introduction}

With the recent discovery of the giant magnetocaloric effect and the beginning of extensive research on the properties of $\mathrm{Gd}_{5}\left(\mathrm{Si}_{\mathrm{x}} \mathrm{Ge}_{1-x}\right)_{4}$, a necessity has developed for a better understanding of the microstructure and crystal structure of this family of rare earth compounds with startling phenomenological properties. The aim of this research is to characterize the microstructure of the $\mathrm{Gd}_{5}\left(\mathrm{Si}_{\mathrm{x}} \mathrm{Ge}_{1-\mathrm{x}}\right)_{4}$, with $\mathrm{X} \cong 2$ and its phase change by using both transmission and electron microscopes. A brief history of past work on $\mathrm{Gd}_{5}\left(\mathrm{Si}_{\mathrm{x}} \mathrm{Ge}_{1-x}\right)_{4}$ is necessary to understand this research in its proper context.

\section{History}

$\mathrm{Gd}_{5}\left(\mathrm{Si}_{\mathrm{x}} \mathrm{Ge}_{1-\mathrm{x}}\right)_{4}$ is a family of rare earth line compounds ranging from $\mathrm{Gd}_{5} \mathrm{Si}_{4}$ to $\mathrm{Gd}_{5} \mathrm{Ge}_{4}$. This family of compounds was first investigated by Smith, et al. [1] and Holtzberg, et al. [2] in 1966 and 1967, respectively. Smith's study was a general survey of the room temperature crystal structure of this compound and several others. Holtzberg's research confirmed the $x$-ray data collected by Smith and studied the magnetic properties at varying temperatures. Neither the magnetocaloric, magnetoresistive or magnetostrictive properties were discovered, thus, extensive research on this family of rare earth compounds did not begin until much later.

In 1997 Pecharsky, et al. [3] discovered a second order transition, $T_{\mathfrak{c}}$, followed very closely by a first order phase transition that produced an adiabatic temperature rise 
in the $\mathrm{Gd}_{5} \mathrm{Si}_{2} \mathrm{Ge}_{2}$. In addition, it was determined that the first order transition could be triggered by a magnetic field, producing a magnetocaloric effect at least a factor of 2 greater than any known magnetic material at the time [3]. Subsequent research has shown that by increasing the level of Ge in the compound the temperature of the transitions can be adjusted to anywhere between $276^{\circ} \mathrm{K}$ and $20^{\circ} \mathrm{K}$ [4].

After these observations were published by Pecharsky and Gschneidner extensive research on this material began. One of the first attempts to discern what gives this material its magnetic properties was performed using powder $\mathrm{x}$-ray diffraction [5] to determine the lattice parameters and space groups of $\mathrm{Gd}_{5}\left(\mathrm{Si}_{\mathrm{x}} \mathrm{Ge}_{1-\mathrm{x}}\right)_{4}$ with $\mathrm{x}$ varying from 0 to 1 . With a more extensive examination of $\mathrm{x}$-ray data the atom positions of $\mathrm{Gd}_{5} \mathrm{Si}_{4}$, $\mathrm{Ge}_{5} \mathrm{Si}_{2} \mathrm{Ge}_{2}$ and $\mathrm{Gd}_{5} \mathrm{Ge}_{4}$ compounds were determined. A major obstacle in this study was determining the crystal structure of $\mathrm{Ge}_{5} \mathrm{Si}_{2} \mathrm{Ge}_{2}$. Initially the space group and atomic parameters of $\mathrm{Gd}_{5} \mathrm{Si}_{4}$, and then $\mathrm{Gd}_{5} \mathrm{Ge}_{4}$, was used as a model for a full Rietveld refinement of $\mathrm{Ge}_{5} \mathrm{Si}_{2} \mathrm{Ge}_{2}$. However, neither of these models could be refined to fit the data collected from the intermediate compound. This indicated that $\mathrm{Ge}_{5} \mathrm{Si}_{2} \mathrm{Ge}_{2}$ had a structure quite different from $\mathrm{Gd}_{5} \mathrm{Si}_{4}$ and $\mathrm{Gd}_{5} \mathrm{Ge}_{4}$.

Because a good initial model of $\mathrm{Ge}_{5} \mathrm{Si}_{2} \mathrm{Ge}_{2}$ could not be produced, and because of the materials complex crystal structure, powder diffraction could not be used to fully determine the compound's crystal structure. Instead, $x$-ray diffraction of a single crystal 
was used to fully refine $\mathrm{Ge}_{5} \mathrm{Si}_{2} \mathrm{Ge}_{2}$. The $\mathrm{x}$-ray diffraction revealed that all examined specimens of $\mathrm{Ge}_{5} \mathrm{Si}_{2} \mathrm{Ge}_{2}$ were twinned, resulting in an average full width of the diffraction peaks during $\omega$-scans approaching $1.5^{\circ}$ for $\mathrm{MoK}_{\mathrm{\alpha}}$ radiation at Bragg angles $(2 \theta)$ between 15 and $25^{\circ}$. The twins resulted in some partial, and some complete, overlapping of peaks, meaning that the diffraction data that was collected contained some ambiguous points. Nonetheless, the partial data collected was consistent with a monoclinic unit cell varying from the $\mathrm{Gd}_{5} \mathrm{Si}_{4}$ orthorhombic unit cell in that $\gamma=93.26^{\circ}$, not $90^{\circ}$. The determined crystal structures revealed that the level of bonding in $\mathrm{Gd}_{5} \mathrm{Ge}_{4}$ was less than in $\mathrm{Gd}_{5} \mathrm{Si}_{4}$ with $\mathrm{Ge}_{5} \mathrm{Si}_{2} \mathrm{Ge}_{2}$ falling between the two. Consequently the change in magnetic properties must be caused by variances in the level of bonding between the atoms within the structure. After the properties of the $\mathrm{Gd}_{5}\left(\mathrm{Si}_{\mathrm{x}} \mathrm{Ge}_{1-\mathrm{x}}\right)_{4}$ family were reported, a study [6] on $\mathrm{Gd}_{5}\left(\mathrm{Si}_{1.8} \mathrm{Ge}_{2.2}\right)$ was preformed to gain a better understanding of what caused the magnetocaloric effect. This study used $\mathrm{x}$-ray powder diffraction and linear thermalexpansion measurements between 200 and $300^{\circ} \mathrm{K}$. These results brought to light that the magnetocaloric effect in the $\mathrm{Gd}_{5}\left(\mathrm{Si}_{1.8} \mathrm{Ge}_{2.2}\right)$ resulted from a single first-order magnetic , phase transition from monoclinic to orthorhombic, and not two transitions as first reported. It also demonstrated that the phase change from monoclinic to orthorhombic caused a reduction in volume, meaning that $\mathrm{Gd}_{5}\left(\mathrm{Si}_{1.8} \mathrm{Ge}_{2.2}\right)$ was not only magnetocaloric 
but also magnetostrictive. Subsequent research [7] discovered $\mathrm{Gd}_{5}\left(\mathrm{Si}_{1.8} \mathrm{Ge}_{2.2}\right)$ was also magnetoresistant.

Single crystal $x$-ray diffraction of $\mathrm{Gd}_{5} \mathrm{Si}_{2} \mathrm{Ge}_{2}$ above and below the material's transition temperature has resulted in a better understanding of the complex nature of this material's structure [8]. This study for the first time accurately described the crystallographic nature of the twins reported in [5], a description that has since been confirmed by electron diffraction(see chapter 3 ). Hence, the nature of the twinning in this structure is now known and a full crystallographic refinement of the atom positions in the orthorhombic unit cell now exists. This data has resulted in a better understanding of the driving force behind the transition. This, in turn, has led to a greater understanding of why the magnetic properties of $\mathrm{Gd}_{5} \mathrm{Si}_{2} \mathrm{Ge}_{2}$ change from paramagnetic at room temperature to ferromagnetic at low temperatures.

Recent research has uncovered that $\mathrm{Gd}_{5}\left(\mathrm{Si}_{\mathrm{x}} \mathrm{Ge}_{1-\mathrm{x}}\right)_{4}, \mathrm{X}$ below 0.5 , also goes through a high temperature transformation [12]. The high temperature phase change is also from monoclinic, P112 1 a, to orthorhombic, Pnma. However, unlike the low temperature transformation this one is irreversible, lethargic and has slightly different lattice parameters. X-ray photoelectron spectroscopy (XPS) has also been used to gain a better understanding of $\mathrm{Gd}_{5}\left(\mathrm{Si}_{\mathrm{x}} \mathrm{Ge}_{1-\mathrm{x}}\right)_{4}$ 's magnetic properties at varying temperatures and compositions [8]. 
One study on the microstructure of $\mathrm{Gd}_{5}\left(\mathrm{Si}_{\mathrm{x}} \mathrm{Ge}_{1-x}\right)_{4}$ [9] was performed using crystals grown by the Czochralski method. The "as grown" plate-like surfaces of crystals were ion sputtered and then examined using scanning electron microscopy (SEM) and Auger electron microscopy (AES). A structure of regular parallel lines was found on the surface of the crystals and AES shown that the features had an increase of oxygen and gadolinium compared to the matrix. The authors were able to determined that the structure of regular parallel lines were not grain boundaries and that the lines were aligned along the main [100] and [001] crystallographic directions. However, no evidence was presented to show whether the surface features noted were present in bulk, and there was no conclusion as to whether these features.were a true second phase or a surface artifact.

An extensive body of work also exists concerning the overall mechanics of the phase transformation, the materials magnetocaloric effect, and magnetic refrigeration in general $[11-12][3,4,13-20]$, while the material's magnetorestriction $[6,21]$ and magnetoresistance $[7,22-24]$ properties have also been researched.

In an effort to make magnetic refrigeration commercially viable, Gschneidner, et al. developed a process to produce large quantities of $\mathrm{Gd}_{5}\left(\mathrm{Si}_{\mathrm{x}} \mathrm{Ge}_{1-\mathrm{x}}\right)_{4}$ [25]. To accomplish this four major obstacles were overcome: 1) Finding a crucible material that would not be completely destroyed by the Gadolinium and allow for easy removal of the product. 
2) Developing a process to remove interstitial impurities, especially carbon, so that the magnetocaloric effect was maintained. 3) Preventing segregation of Si rich phases caused by incongruent solidification. 4) Finding a way to avoid a eutectic decomposition during cooling of the material.

\section{Crystal Structure}

The crystal structure of $\mathrm{Gd}_{5}\left(\mathrm{Si}_{x} \mathrm{Ge}_{1-x}\right)_{4}$ has been described as sub-nanometer thick slabs [11] that extend for infinity in the a and $c$ directions. At room temperature, $\mathrm{Gd}_{5} \mathrm{Si}_{4}$, Figure 1.1 (b), is ferromagnetic and has an orthorhombic crystal structure in which all the slabs are interconnected by partially covalent $\mathrm{Si}-\mathrm{Si}$ bonds. $\mathrm{Gd}_{5} \mathrm{Ge}_{4}$, Figure 1.1 (d), has the same orthorhombic structure as $\mathrm{Gd}_{5} \mathrm{Si}_{4}$ except that the Ge atoms occupy the Si lattice positions and do not form bonds between the slabs. As Ge is substituted for $\mathrm{Si}$ in $\mathrm{Gd}_{5} \mathrm{Si}_{4}$ making $\mathrm{Gd}_{5}\left(\mathrm{Si}_{\mathrm{x}} \mathrm{Ge}_{\mathrm{i}-\mathrm{x}}\right)_{4}, \mathrm{X}$ less than 1 , the partially covalent bond between the slabs remains until X reaches 0.5 . 


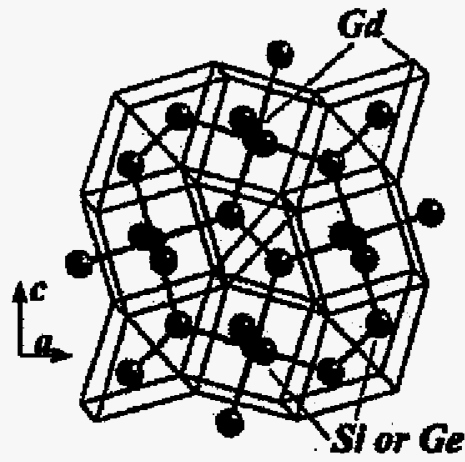

a

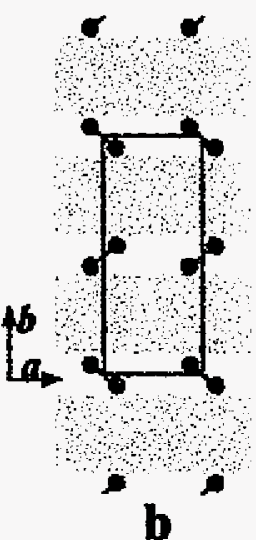

b

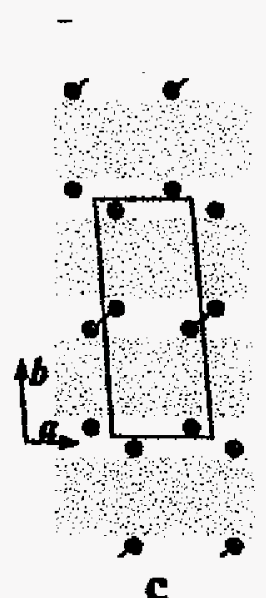

c

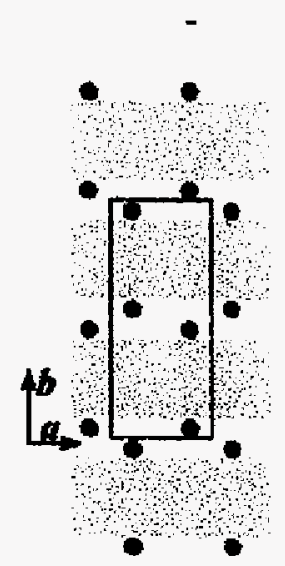

d

Figure 1.1. An illustration of the crystal structure of $\mathrm{Gd}_{5}\left(\mathrm{Si}_{\mathrm{x}} \mathrm{Ge}_{1-\mathrm{x}}\right)_{4}$ as it varies by composition. (a) Shows the configuration of the slab and (b) $0.5<x<1$, (c) $0.24<x<0.5$, and (d) $0<x 0.2$, illustrate the view orthogonal to the slab. [From Vitalij K. Pecharsky and Karl A. Gschneidner Jr., Advanced Materials, 2001, 13, No. 9, May 3]

1.1 (c) and the material goes from being ferromagnetic to paramagnetic. Along with the change in the material's magnetic state, its crystal structure changes from orthorhombic, Pnma, to monoclinic, $\mathrm{P} 112_{1} / \mathrm{a} . \mathrm{Gd}_{5}\left(\mathrm{Si}_{\mathrm{x}} \mathrm{Ge}_{1-\mathrm{x}}\right)_{4}$ remains monoclinic until X reaches 24 . From .24 to .20 there is a region of uncertainty of the material's properties because of insufficient data. Once $\mathrm{X}$ is below .20 the compound's structure is that of $\mathrm{Gd}_{5} \mathrm{Ge}_{4}$. 


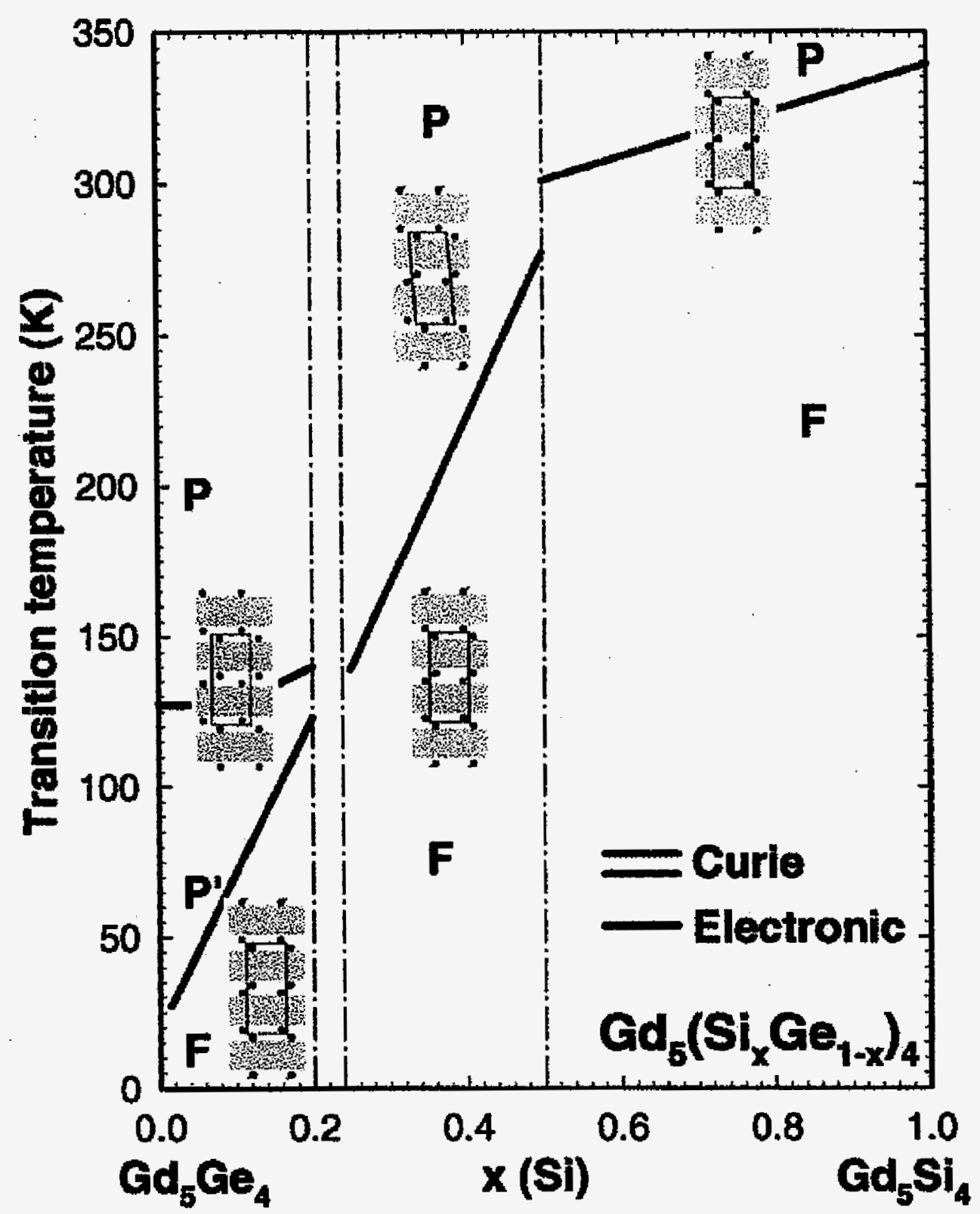

Figure 1.2. A pseudo-phase diagram, of the crystal structure and magnetic classification vs. temperature and composition. The green line corresponds to a secondorder paramagnetic (P) to ferromagnetic (F) phase transition when $0.5<\mathrm{x}<$ 1. The blue line is a second order paramagnetic $(\mathrm{P})$ electric phase transition to $\left(P^{\prime}\right)$ when $0 \leq x \leq 0.2$. The red lines are first-order ferromagnetic to paramagnetic ( $F$ to $\left.P^{\prime}\right)$ and $(F$ to $P$ ) phase transitions when $0 \leq x \leq 0.2$ and $0.24 \leq \mathrm{x} \leq 0.5$ [From Vitalij K. Pecharsky and Karl A. Gschneidner Jr., Advanced Materials, 2001, 13, No. 9, May 3] 


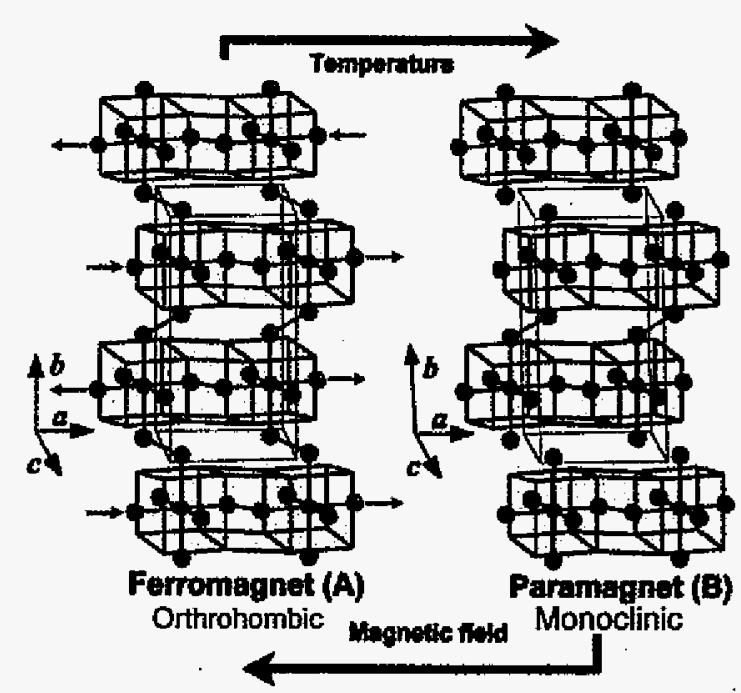

(a)

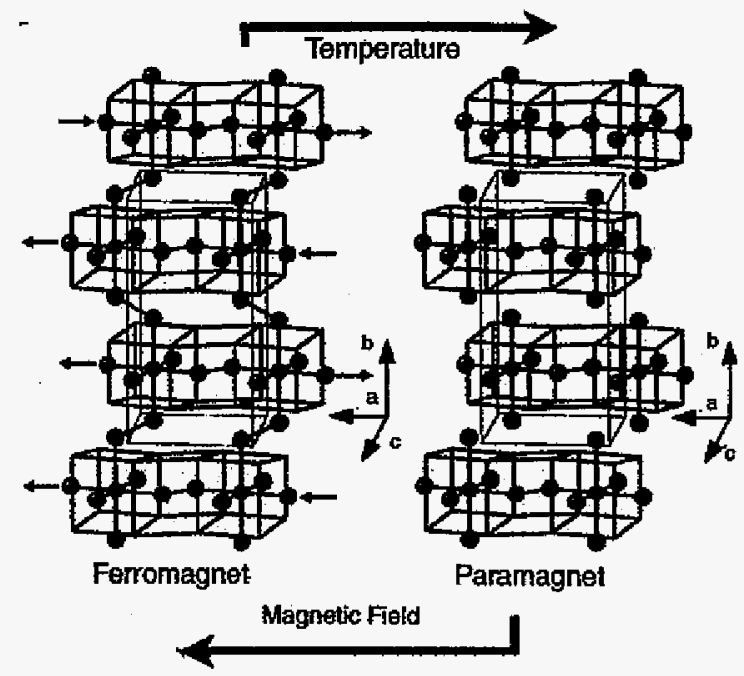

(b)

Figure 1.3. A drawing illustrating the breaking and reforming of the bonds between the slabs of $\mathrm{Gd}_{5}\left(\mathrm{Si}_{\mathrm{x}} \mathrm{Ge}_{1-\mathrm{x}}\right)_{4^{-}}$(a) $\mathrm{x}$ between 0.24 and 0.5 (b) $\mathrm{x}$ between 0 and 0.2 [From Vitalij K. Pecharsky and Karl A. Gschneidner Jr., Advanced Materials, 2001, 13, No. 9, May 3]

What makes $\mathrm{Gd}_{5}\left(\mathrm{Si}_{\mathrm{x}} \mathrm{Ge}_{1-\mathrm{x}}\right)_{4} \mathrm{X} \leq 0.5$ an exciting material to study is that by changing the temperature and/or exposing the compound to a magnetic field the broken bonds between the slabs are reformed, as shown in Figure 1.3, to bring about the phase change that was first reported. The repeated breaking and reforming of bonds between the slabs is what gives the material it magnetocaloric, magnetoresistive and magnetostrictive properties. The extent to which the conditions have to be changed to reform the bonds also is directly dependent upon the amount of Ge that has been substituted for Si, as shown in Figure 1.2. 


\section{Chapter 2. SEM Analysis}

The goal of this chapter is to determine if the lines observed by Szade, et al. are a surface feature associated with the growth of the crystals or a second phase existing throughout the bulk of the material.

Experimental Details

Samples were prepared with the composition $\mathrm{Gd}_{5} \mathrm{Si}_{1.95} \mathrm{Ge}_{2.05}$, using $99.90 \mathrm{wt} \%$ pure Gd on bases of metals, 99 wt.\% pure when considering interstitial impurities ("commercial grade" Gd), and 99.9999 wt.\% pure, metals and intersitials, Si and Ge. This composition was chosen rather than $\mathrm{Gd}_{5} \mathrm{Si}_{2} \mathrm{Ge}_{2}$ to ensure that the alloy was in the giant magnetocaloric region. An ingot $\cong 1 \mathrm{~kg}$ was produced by induction melting of the stoichiometric mixture of $\mathrm{Gd}, \mathrm{Si}$ and $\mathrm{Ge}$ in a vacuum of $\sim 10^{-6}$ torr in a Ta crucible. The compound was held molten at $1800^{\circ} \mathrm{C}$ for 1 hour to remove interstitial impurities, then cooled below the melting point to $1400^{\circ} \mathrm{C}$ where it was held for 1 hour to homogenize the structure. The sample was then cooled to room temperature by turning off the power of the induction furnace [8]. After cooling the ingot was broken up and pieces were selected at random to ensure a representative cross-section of the ingot was examined.

A small number of arc melted samples were also examined. After melting the samples were given a homogenization heat treatment as were the bulk samples. The 
same furnace was used, however the samples were only taken to $1300^{\circ} \mathrm{C}$ for $1 \mathrm{hr}$. then furnace cooled under vacuum. Although the size of the arc-melted button was substantially less than that of the bulk ingot, the cooling rate maintained in the furnace for both materials was essentially identical. The target composition of these samples was Gd5Si2Ge2 and the initial Gd constituent was of highest purity, being 99.99 wt.\% pure for both metals and interstitials. The Gd metal was prepared by the Materials Preparation Center of the Ames Laboratory.

Examination of all samples was performed using optical microscopy, SEM, utilizing energy dispersive spectroscopy (EDS), and orientation imaging microscopy (OIM). Samples were examined in the as-received condition, in the polished condition and in the cut and polished condition both before and after ion and acid etching. The asreceived condition involved direct examination of faceted surfaces where the sample was unaltered in any way.

$\underline{\text { Results }}$

The faceted surfaces of an as-received sample are shown in Fig. 1. The linear features noted by Szade, et al. are seen along with a number of impurity phases. Ta silicide crystals, Fig. 2.1a, identified as $\mathrm{Ta}_{2} \mathrm{Si}$ using EDS, Fig. 2.2, and x-ray diffraction, appeared as small faceted crystals within the $\mathrm{Gd}_{5}\left(\mathrm{Si}_{1.95}, \mathrm{Ge}_{2.05}\right)$ matrix. This phase forms 
by reaction of the constituents with the Ta crucible used. A second phase consisting of about 35 at\% $\mathrm{Si}, 15$ at\% $\mathrm{Ge}$ and 50 at\% Gd as determined using EDS, Fig. 2.3, and identified as $\mathrm{Gd}_{1}(\mathrm{Si}, \mathrm{Ge})_{1}$ can also been seen as the darker, leaf-like structure of Fig. 2.1a.

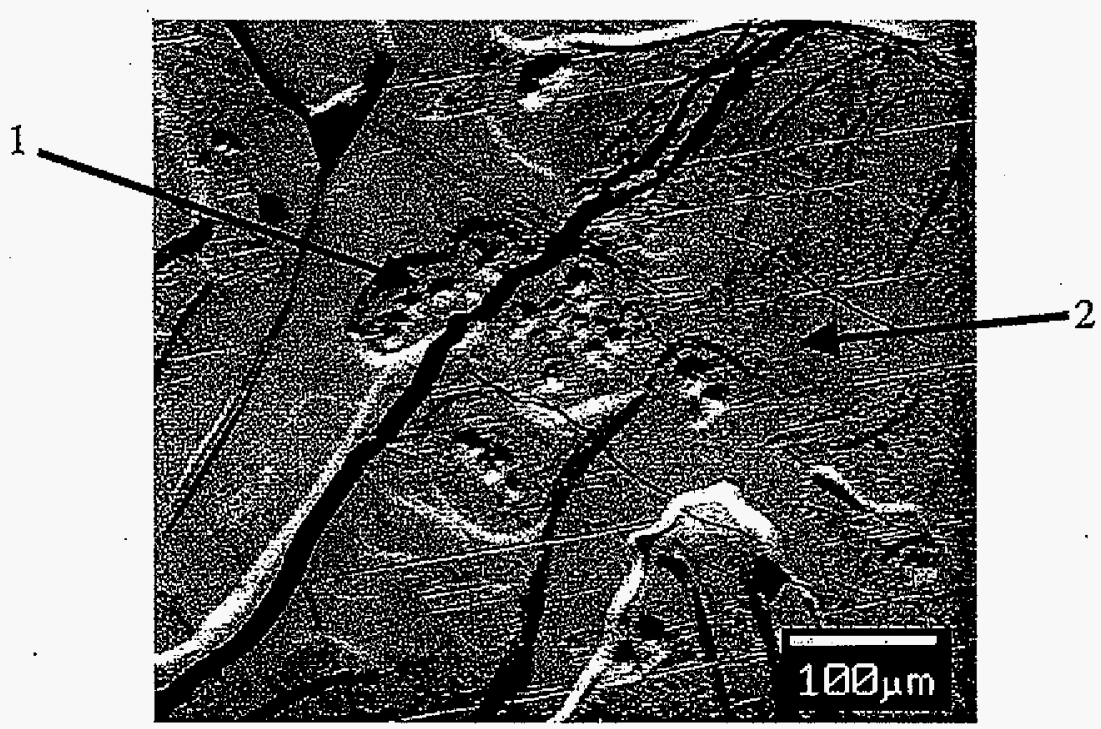

(a)

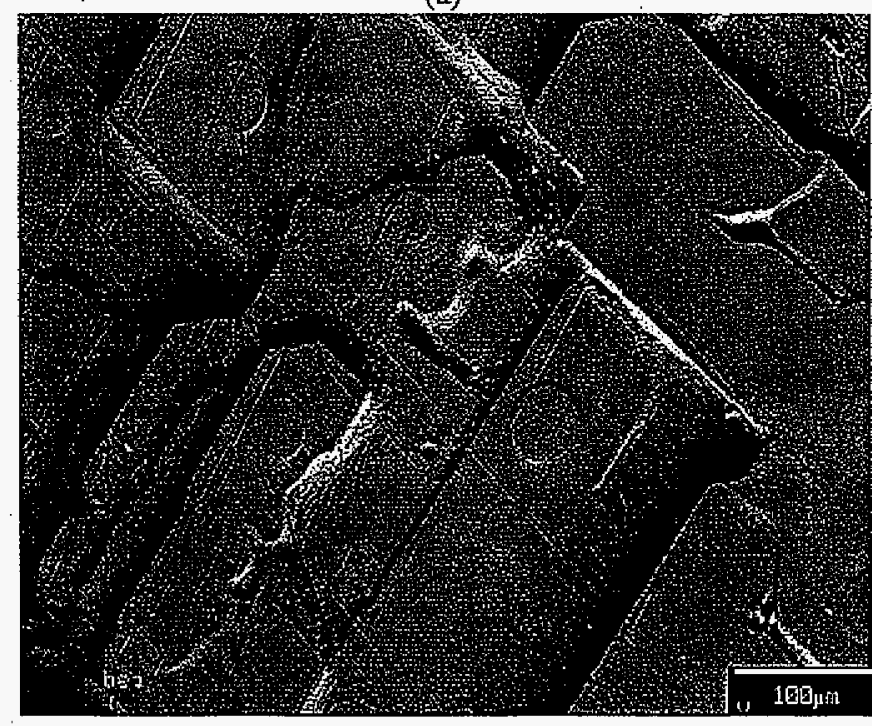

(b)

Figure 2.1. Examination of samples in the as-received state. a) Note the presence of linear features, Ta-silicide crystals (arrowed as 1), and the $\mathrm{Gd}_{1}(\mathrm{Si}, \mathrm{Ge})_{1}$ second phase (arrowed as 2). b) A second view showing growth steps of the crystal. The linear features and regions of $\mathrm{Gd}_{1}(\mathrm{Si}, \mathrm{Ge})_{1}$ are evident. 


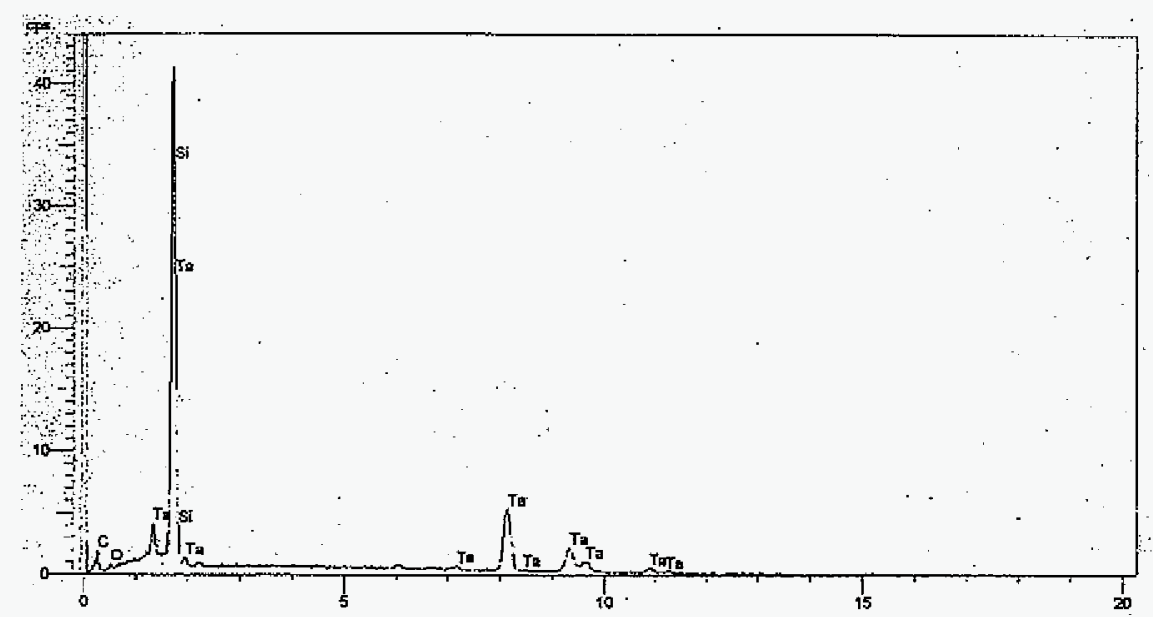

Figure 2.2: EDS spectrum, taken on a polished sample, of a crystal with the same composition as the one pointed out on Fig. 2.1(a).

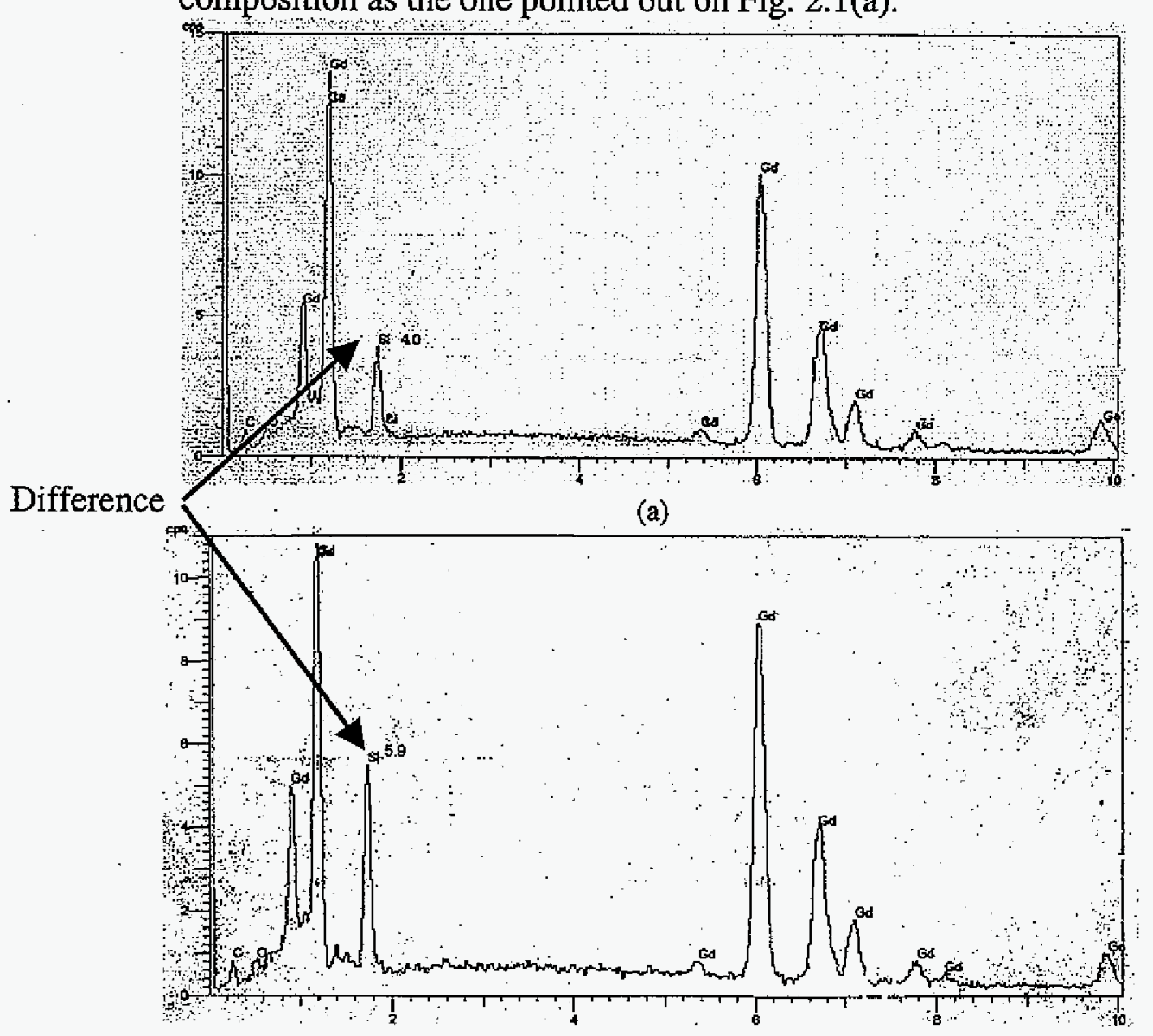

(b)

Figure 2.3: EDS spectra taken on polished sample, (a) from the matrix and (b) from the "leafy" phase pointed out as two on Figure 1(a). 


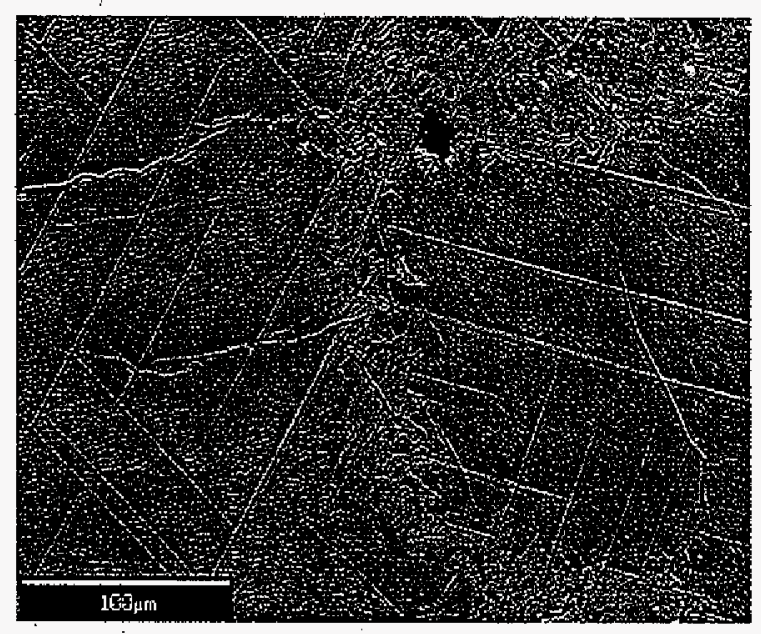

(a)

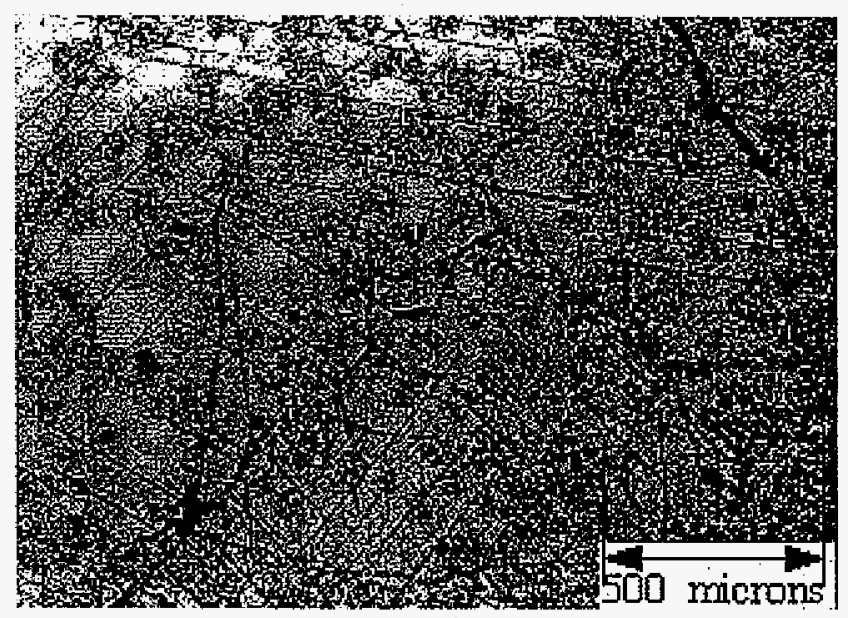

(b)

Figure 2.4. a) Polished and ion etched sample, SEM micrograph. The linear features and $\mathrm{Gd}_{1}(\mathrm{Si}, \mathrm{Ge})_{1}$ second phase are evident. b) Polished and acid etched sample, optical micrograph. Linear features are seen, as are surface corrosion products.

The linear features were not clearly observed in all samples in the as-received state. However, they all contained regions that hinted at their presence, suggesting that if properly polished the features might be seen in all samples. The linear features were visible in the as-polished samples, however, the features were so fine that they were 
difficult to examine using an optical microscope and were only visible in the SEM at relatively high magnification. To make the linear features more visible two different steps were taken, namely, ion milling and acid etching. These results are shown in Fig. 2.4.

In both instances the linear features are evident; the $\mathrm{Gd}_{1}(\mathrm{Si}, \mathrm{Ge})_{1}$ second phase is also seen in the ion etched sample. The acid etching unfortunately introduces a surface corrosion product that obscures much of the microstructure. However, grain boundaries can be deduced by observation of the directionality of the linear features. In Fig. 2.3 (b) the presence of a triple point can be deduced by observing the three distinct areas that contain the linear features.

Once it was ascertained that the linear features were present in all samples, EDS scans were performed across them. A typical scan is shown in Fig. 2.5. An increase in $\mathrm{Gd}$ and $\mathrm{O}$ is seen along with a corresponding drop in Si. This differs slightly from the results of Szade, et al. [9] where a drop in both $\mathrm{Si}$ and Ge was seen using Auger spectroscopy. If the $O$ content is assumed to be due to surface oxidation, and is ignored from composition calculations, the relative atomic percentages of the constituents are 60 at\% Gd, 15 at\% $\mathrm{Si}$, and 25 at\% Ge. This corresponds to the $\mathrm{Gd}_{5}(\mathrm{Si}, \mathrm{Ge})_{3}$ composition. 


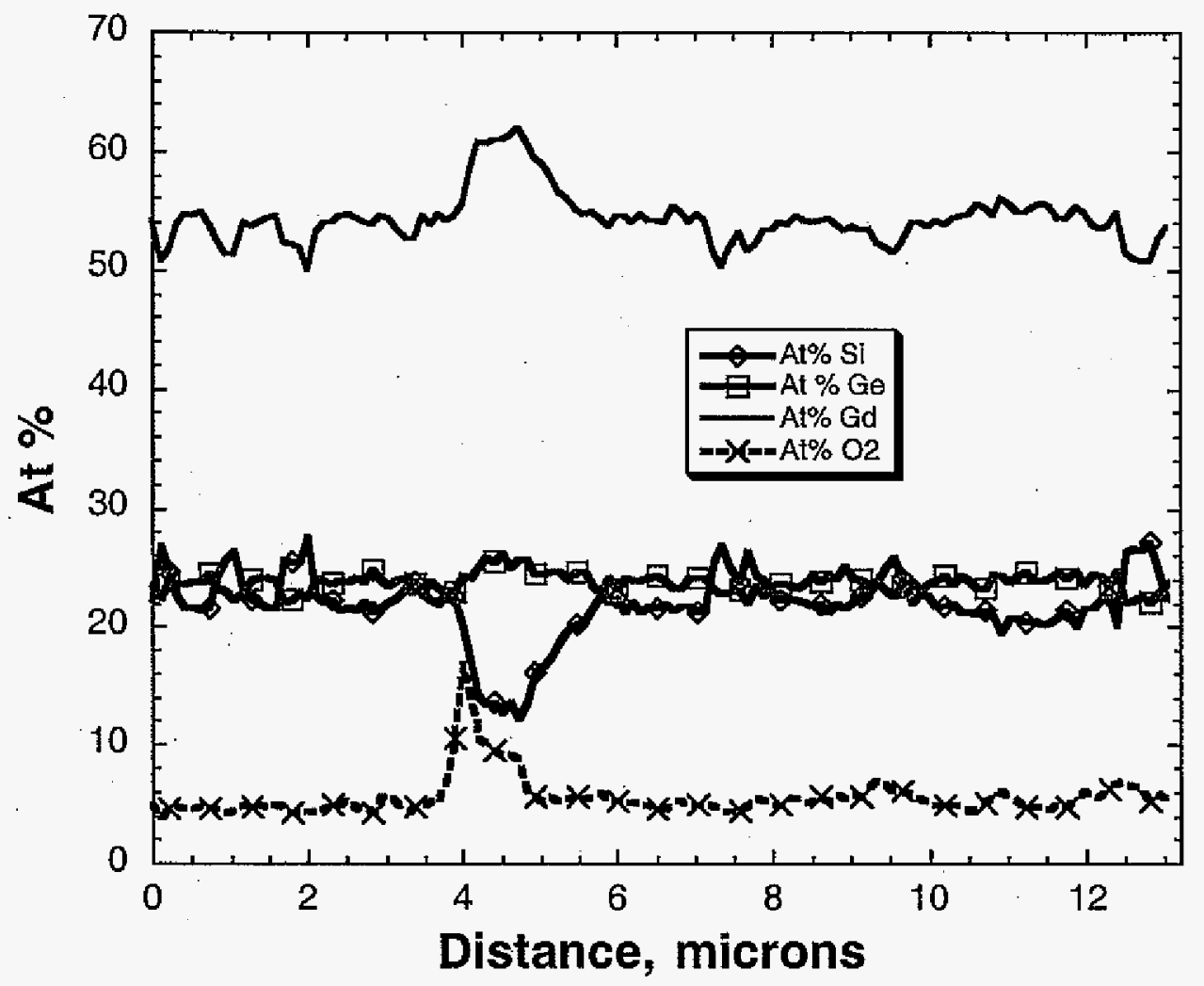

Figure 2.5. Typical $x$-ray results obtained from a linear feature before ion etching.

\section{Discussion}

Examination of the $\mathrm{Gd}_{5}\left(\mathrm{Si}_{1.95} \mathrm{Ge}_{2.05}\right)$ induction melted samples in as-received, polished, and polished and etched conditions revealed a $\mathrm{Gd}_{1}(\mathrm{Si}, \mathrm{Ge})_{1}$ second phase, impurities such as Ta silicide crystals from crucible materials, and an array of linear features similar to those first observed by Szade, et al. [9]. The linear features were found throughout the bulk of the ingot, in sectioned and polished samples, indicating that the features are not a surface or growth affect. Quantitative microscopy revealed the 
volume percentage of the features to be on average 3 vol\%. The angular relationship noted in [9] was observed to be constant within each grain, as illustrated by the triple point of Fig. 2.3b. X-ray EDS measurements confirm that the features have a different composition than the bulk, being approximately $\mathrm{Gd}_{5}(\mathrm{Si}, \mathrm{Ge})_{3}$. The bulk nature and crystallographically oriented appearance, and the distinctly different composition lead to the conclusion that the linear features are a separate phase forming in a manner indicative of a Widmanstätten structure. The phase appears to grow as long rods of extremely small diameter along the $[100]$ and [001] crystallographic directions.

The phases observed in this system can be understood by an examination of the binary systems that comprise the ternary alloy. Both the Gd-Si and Gd-Ge binary systems exhibit 1-1 and 5-3 line compounds. In the Gd-Si-Ge ternary the second phase noted corresponds to a $\mathrm{Si}-\mathrm{Ge}$ equivalent of the 1-1 compounds while the Widmanstattten structure corresponds to the 5-3 compounds.

If the linear features are a Widmanstätten structure then it should be possible to suppress, or substantially reduce, the appearance of the phase by proper control of the chemical composition. The complexity of the Gd-Si-Ge ternary system makes it difficult to control the composition and solidification kinetics in a bulk induction melted ingot. However, small arc-melted samples where the composition of the constituents is more closely controlled may be expected to provide better control over the resulting 
microstructure. As a test of this hypothesis, arc melted samples of $\mathrm{Gd}_{5} \mathrm{Si}_{2} \mathrm{Ge}_{2}$ were also examined. These samples had a target composition of $\mathrm{Gd}_{5} \mathrm{Si}_{2} \mathrm{Ge}_{2}$, and used purer starting constituents. Results are shown in Fig.2.7. Optical and SEM observation of the microstructure showed no sign of the linear features. $\mathrm{X}$-ray diffraction analysis confirmed that the button only showed peaks for $\mathrm{Gd}_{5} \mathrm{Si}_{2} \mathrm{Ge}_{2}$ and magnetocaloric measurements confirmed a single crystallographic transition existed, indicative of a highly-homogenous, single-phase material. The fact that the samples were subjected to a high temperature heat treatment followed by a slow cool (similar to the bulk ingot) suggests that the Widmanstätten structure has been avoided rather than merely suppressed by a high cooling rate. The $\mathrm{Ta}_{2} \mathrm{Si}$ impurity and $\mathrm{Gd}_{1}(\mathrm{Si}, \mathrm{Ge})_{1}$ phases are gone along with the Widmanstätten structure. 


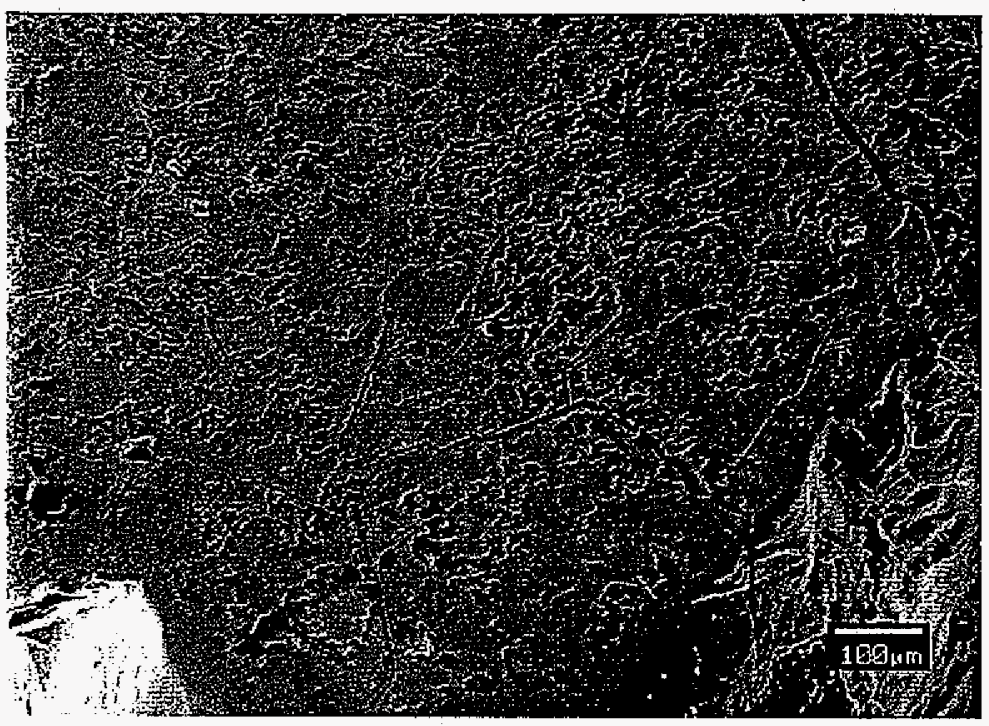

Figure 2.7. Secondary electron image of $\mathrm{Gd}_{5} \mathrm{Si}_{2} \mathrm{Ge}_{2}$ arc melted sample, acid etched. Visible are cracks and a reaction product layer, however, no Widmanstätten features are visible.

\section{Summary and Conclusions}

Preliminary studies have shown that Gd-Si-Ge magnetocaloric alloys contain a great amount of promising properties for today's industry. Examination of one such alloy, $\mathrm{Gd}_{5}\left(\mathrm{Si}_{1.95} \mathrm{Ge}_{2.05}\right)$, yielded the following results:

1. Samples produced using induction melting and commercially available Gd, duplicating the techniques that would be utilized by industry, showed that various contaminant and second phases were produced along with the desired $\mathrm{Gd}_{5}\left(\mathrm{Si}_{1.95} \mathrm{Ge}_{2.05}\right)$ matrix. These phases included $\mathrm{Gd}_{1}(\mathrm{Si}, \mathrm{Ge})_{1}, \mathrm{Ta}_{2} \mathrm{Si}$ crystals that are a result of reaction with the crucible, and a linear feature that is present throughout the bulk of the ingot. 
2. The linear feature is crystallographically orientated with respect to the crystal and possesses a composition near $\mathrm{Gd}_{5}(\mathrm{Si}, \mathrm{Ge})_{3}$. These characteristics, plus the bulk nature of the feature, suggest that the feature is a Widmanstätten structure of $\mathrm{Gd}_{5}(\mathrm{Si}, \mathrm{Ge})_{3}$ rods.

3. Arc melted samples, where the composition and cooling could be more tightly controlled, failed to show any of the $\mathrm{Gd}_{5}(\mathrm{Si}, \mathrm{Ge})_{3}$. These results support the hypothesis that the linear feature is a Widmanstätten phase.

4. It is not known yet what affect the Widmanstätten structure has on the magnetocaloric properties. However, fabrication of single $\mathrm{Gd}_{5}\left(\mathrm{Si}_{\mathrm{x}} \mathrm{Ge}_{\mathrm{I-x}}\right)_{4}$ for industrial use will require tight control of the starting material and production process. 


\title{
Chapter 3. A Microstructural Analysis of Twinned $\beta$ - $\mathrm{Gd}_{5} \mathrm{Si}_{2} \mathrm{Ge}_{2}$
}

\author{
A paper submitted to the Journal Physical Review Letters B \\ John Meyers, ${ }^{a, 1}$ Scott Chumbley, ${ }^{a, 2} *$ Wonyoung Choe $e^{b, 3}$ and Gordon J. Miller ${ }^{b, 4} *^{I}$
}

Department of Materials Science and Engineering, ${ }^{a}$ Department of Chemistry ${ }^{\mathrm{b}}$ and Ames Laboratory, US Department of Energy, Iowa State University, Ames, Iowa 50011, USA Abstract

The room-temperature microstructure of the gaint magnetocaloric material, $\mathrm{Gd}_{5} \mathrm{Si}_{2} \mathrm{Ge}_{2}$ is investigated using transmission electron microscope and selected area diffraction. Nonmerohedral twinning is identified and its twin law, which relates one twin component to the other, is revealed. Based on selected area diffraction pattern data, we build a structural model for nonmerohedral twinning and explain its origin in terms of the irregular shear movement of two-dimensional ${ }_{2}^{\infty}\left[G d_{5}\left(S i_{2} G e_{2}\right)\right]$ slabs held together by (Si, Ge) dimers.

\footnotetext{
${ }^{1}$ Primary researcher and Author

${ }^{2}$ Major Professor

${ }^{3} \mathrm{Co}$-Author wrote introduction and developed model of the twin

${ }^{4}$ Associate Professor working with 3.
} 
The material $\mathrm{Gd}_{5} \mathrm{Si}_{2} \mathrm{Ge}_{2}$ is of great interest not only because it shows an unprecedented giant magnetocaloric effect, ${ }^{1}$ which could be used in near-room temperature magnetic refrigeration, ${ }^{2}$ but it also exhibits a remarkable structural transformation from low-temperature orthorhombic $\left(\alpha-\mathrm{Gd}_{5} \mathrm{Si}_{2} \mathrm{Ge}_{2}\right)$ to high-temperature monoclinic symmetry $\left(\beta-\mathrm{Gd}_{5} \mathrm{Si}_{2} \mathrm{Ge}_{2}\right)_{:}^{3,4}$ In the course of the $\alpha \rightarrow \beta$ phase transition, $25 \%$ of the $(\mathrm{Si}, \mathrm{Ge})-(\mathrm{Si}, \mathrm{Ge})$ dimers that exist in the structure break their covalent bonds, resulting in isolated $\mathrm{Si}$ and/or Ge atoms. Furthermore, this breaking and forming of covalently bonded dimers can be repeated by cycling across the transition temperature of $276 \mathrm{~K}^{4}$ This extraordinary phenomenon stems from unique structural motifs found in $\mathrm{Gd}_{5} \mathrm{Si}_{2} \mathrm{Ge}_{2}$ 

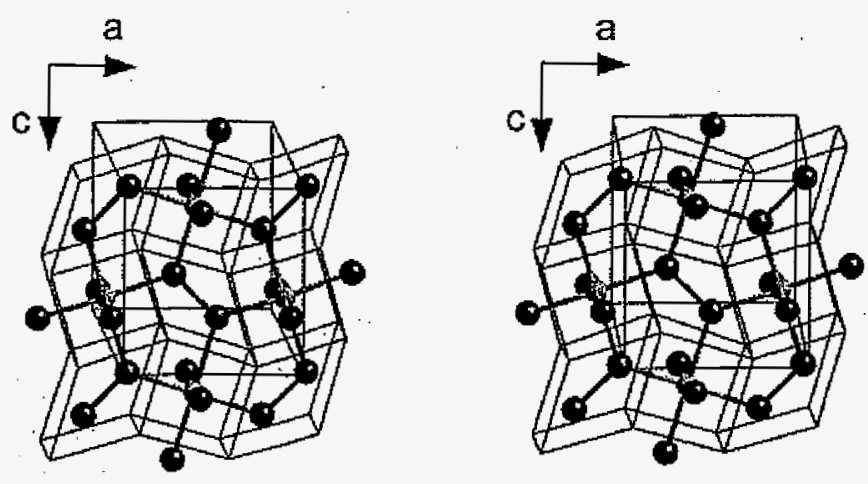

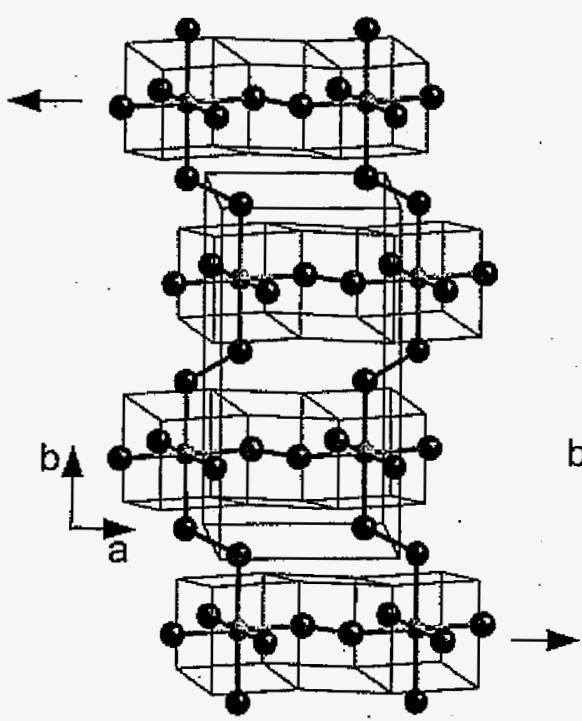

(a)

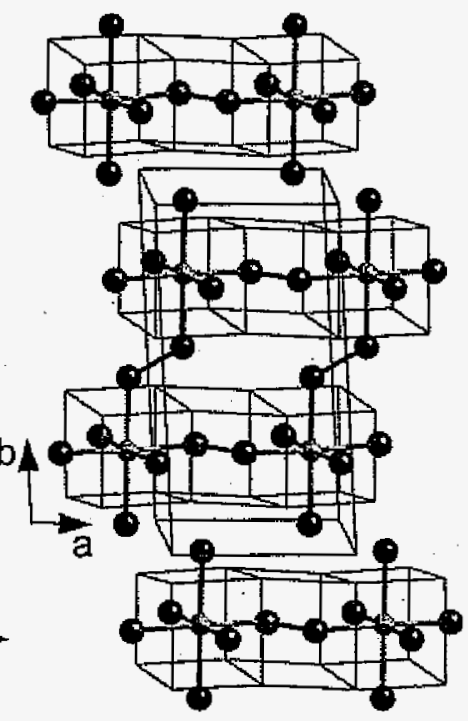

(b)

Figure 3.1. Crystal structures of (a) $\alpha-\mathrm{Gd}_{5} \mathrm{Si}_{2} \mathrm{Ge}_{2}$ and (b) $\beta-\mathrm{Gd}_{5} \mathrm{Si}_{2} \mathrm{Ge}_{2}$ shown along the (010) axis, (top), and (001) axis (bottom). The (001) axis projection emphasizes a shear movement of the ${ }_{2}^{\infty}\left[G d_{5}\left(S i_{2} G e_{2}\right)\right]$ slabs, as well as breaking and forming (Si,Ge)-(Si,Ge) dimers (black circles). Gd atoms are light gray; (Si,Ge) atoms inside the ${ }_{2}^{\infty}\left[\mathrm{Gd}_{5}\left(\mathrm{Si}_{2} \mathrm{Ge}_{2}\right)\right]$ slabs are dark gray. Each slab consists of two $3^{2} 434$ nets of $\mathrm{Gd}$ atoms with additional $\mathrm{Gd}$ atoms in the cubic voids and $(\mathrm{Si}, \mathrm{Ge})$ atoms in the trigonal prismatic voids.

The structures of $\alpha$ - and $\beta-\mathrm{Gd}_{5} \mathrm{Si}_{2} \mathrm{Ge}_{2}$ can be constructed from ${ }_{2}^{\infty}\left[G d_{5}\left(S i_{2} G e_{2}\right)\right]$ slabs held together by (Si,Ge) dimers (see Fig. 3.1a). Upon the $\alpha \rightarrow \beta$ phase transformation, 
these slabs undergo a shear movement along the a direction in the orthorhombic $\alpha$ phase, which breaks one-half of the (Si,Ge)-( $\mathrm{Si}, \mathrm{Ge})$ covalent bonds between the slabs, and becomes the monoclinic $\beta$ phase, as shown in Fig. 1b. Studies on other compositions, $\mathrm{Gd}_{5}\left(\mathrm{Si}_{\mathrm{x}} \mathrm{Ge}_{1-x}\right)_{4}$, and different $\mathrm{Ln}_{5}\left(\mathrm{Si}_{\mathrm{x}} \mathrm{Ge}_{1-\mathrm{x}}\right)_{4}$ systems $(\mathrm{Ln}=\mathrm{Lanthanide})$ indicate that the ${ }_{2}^{\infty}\left[\operatorname{Ln}_{5}\left(\mathrm{Si}_{x} G e_{1-x}\right)_{4}\right]$ slabs are the basic units undergoing shear movements, and also play a pivotal role in the giant magnetocaloric effects of these systems. ${ }^{5}$

Another interesting structural feature in $\beta-\mathrm{Gd}_{5} \mathrm{Si}_{2} \mathrm{Ge}_{2}$ is nonmerohedral twinning, ${ }^{4,6}$ for which only a small portion of reflections from two twin components are exactly superimposed while the remaining reflections are not. The nonmerohedral twinning in $\beta$ $\mathrm{Gd}_{5} \mathrm{Si}_{2} \mathrm{Ge}_{2}$ vanishes and reappears, respectively, as the material is cycled across the transition temperature. ${ }^{4}$ In this communication, we present analysis of the twinned structure of $\beta-\mathrm{Gd}_{5} \mathrm{Si}_{2} \mathrm{Ge}_{2}$ using transmission electron microscopy (TEM) and selected area diffraction (SAD). 


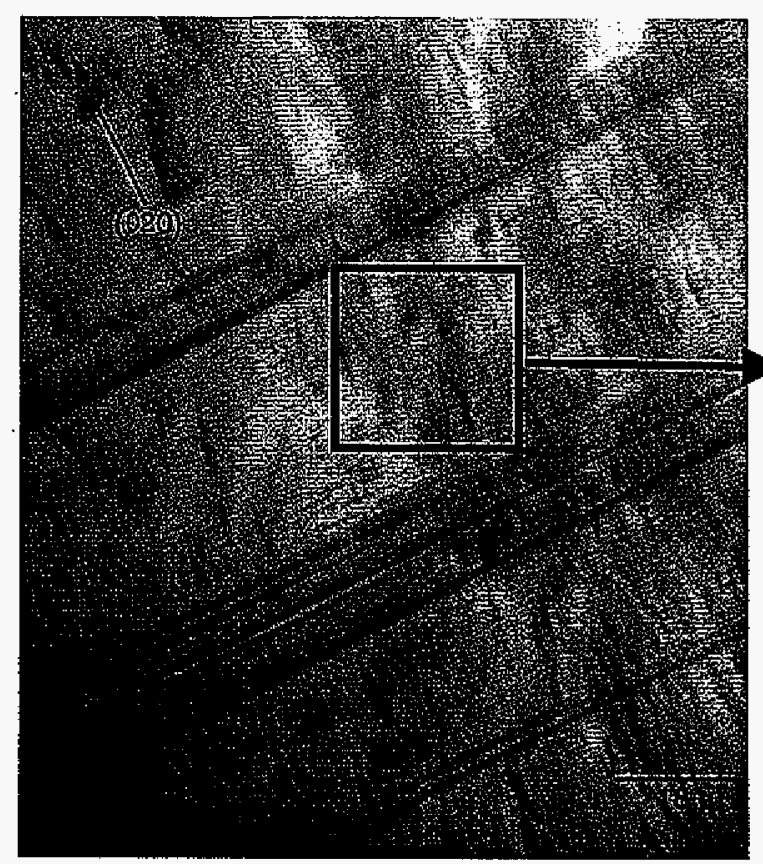

(a)

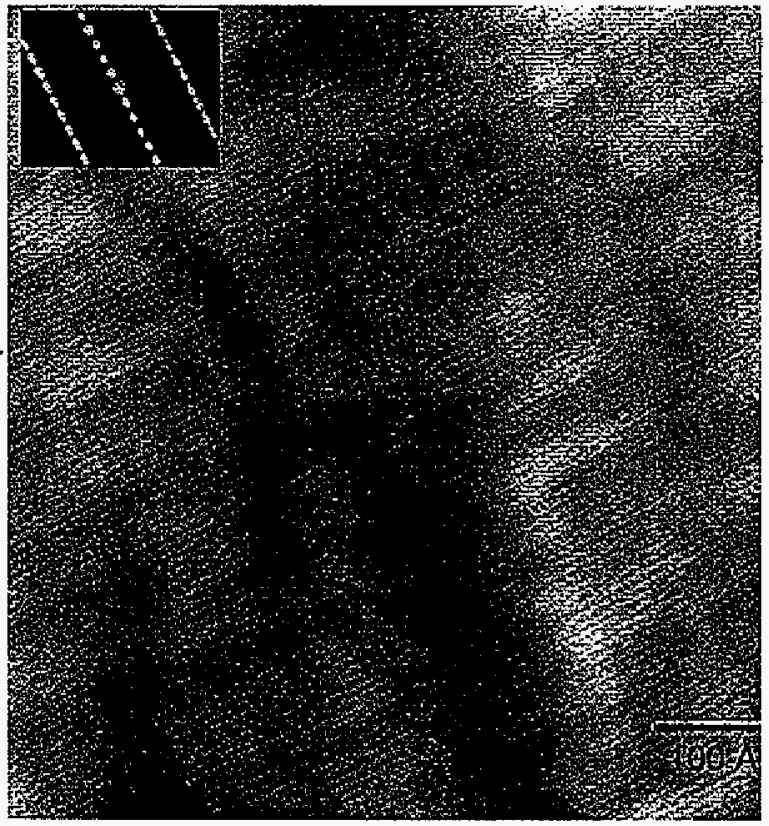

(b)

Figure 3.2. Microstructure of $\beta-\mathrm{Gd}_{5} \mathrm{Si}_{2} \mathrm{Ge}_{2}$ at (a) low and (b) high resolution.

The $\mathrm{Gd}_{5} \mathrm{Si}_{2} \mathrm{Ge}_{2}$ sample examined in this study was prepared by arc-melting its constituent elements (purity; Gd, 99.8\%; Si, 99.99\%; Ge, 99.99\%) in an argon atmosphere on a water-cooled copper hearth. The resulting button was re-melted several times to ensure homogeneity, and then annealed at $1570 \mathrm{~K}$ for $1 \mathrm{~h}$. Scanning electron microscopy (SEM) was used to ensure that the microstructure was homogeneous. The sample was mechanically thinned to $140 \mu$, reinforced with epoxy and a single slit Mo support grid, and then mechanically dimpled until the center was perforated. During the dimpling process the sample was again reinforced with epoxy after cracks started to appear. The sample was ion-milled at $4.5 \mathrm{kV}, 15$ degrees and $1 \mathrm{~mA}$ for $1.5 \mathrm{~h}$, to clean the 
surface. TEM bright field images (BF) and SAD patterns were taken of the sample both off, and on, zone axes.

SEM examination of $\mathrm{Gd}_{5} \mathrm{Si}_{2} \mathrm{Ge}_{2}$ shows no indication of secondary phases, unlike previous studies where various second phases and a linear feature were observed. ${ }^{7,8}$ The microstructure of the material is shown in Figure 3.2. Two features can be seen, what appears to be a sharply faulted structure is immediately obvious while a much finer diffuse lamellar structure can be observed across the entire region Fig. 3.22a. SAD patterns were obtained from areas containing only the lamellae, the apparent faults plus lamellae, and overlapping a fault boundary. No differences were observed between these respective SADs, in all cases the patterns matched well with predicted patterns of $\beta$ $\mathrm{Gd}_{5} \mathrm{Si}_{2} \mathrm{Ge}_{2}$, supporting the conclusion that structures observed here are not due to the formation of any secondary phases. High resolution imaging of the structure, Fig. $3.2 \mathrm{~b}$, shows that both the sharp fault-like structure and the diffuse lamellae streaks are parallel to the $(020)$ planes. 


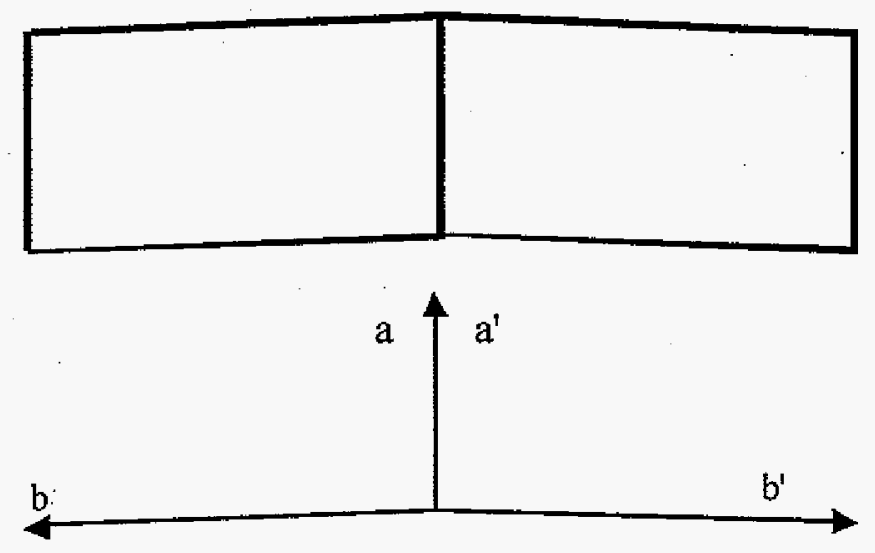

Figure 3.3. Scheme for the twin law found in $\beta-\mathrm{Gd}_{5} \mathrm{Si}_{2} \mathrm{Ge}_{2}$. The twin axis is the [100] crystallographic axis with $\boldsymbol{b}^{\prime}=\boldsymbol{b}+\boldsymbol{a}(2 b \cos \gamma) / a$ where $(2 b \cos \gamma) / a=$ $-0.2229, a=7.5891(17) \AA, b=14.827 \AA, c=7.7862 \AA$, and $\gamma=93.262(4)^{\circ}$. Cell parameters are from Ref. 4 .

$\mathrm{SAD}$ patterns obtained from the sample confirm the twin patterns in $\beta-\mathrm{Gd}_{5} \mathrm{Si}_{2} \mathrm{Ge}_{2}$, as suggested in the single crystal structure study. ${ }^{4}$ The twin observed in $\beta-\mathrm{Gd}_{5} \mathrm{Si}_{2} \mathrm{Ge}_{2}$ is a rotational twin with respect to the $[100]$ axis (see Fig. 3.3). The twin law, which transforms one twin component to the other, can be seen as follows.

$$
\begin{aligned}
& a^{\prime}=a \\
& b^{\prime}=b+a\left(\frac{2 b}{a}\right) \cos \gamma \cong b-0.2229 a \cong b-\frac{2}{9} a \\
& c^{\prime}=-c \\
& \left(\begin{array}{l}
a^{\prime} \\
b^{\prime} \\
c^{\prime}
\end{array}\right)=\left(\begin{array}{ccc}
1 & 0 & 0 \\
-2 / 9 & 1 & 0 \\
0 & 0 & 1
\end{array}\right)\left(\begin{array}{l}
a \\
b \\
c
\end{array}\right)
\end{aligned}
$$

Because of this twin relationship, $\boldsymbol{b}^{\prime}=\boldsymbol{b}-(2 / 9) a, k^{\prime}=k-(2 / 9) h$ and reflections from the two twin domains coincide almost exactly when $|h|=0$ or 9 . When $|h|=4$ or 5 , the 
reflections are so close that in most cases they significantly overlap one another. In Fig. $3.4 \mathrm{a}$, the $(200)$ reflection has a satellite at $(2,-4 / 9,0)$, due to nonmerohedral twinning governed by the twin law above. The angle between the two twin cells is $5.7^{\circ}$, which compares well with the value calculated from the single crystal data, i.e., $\left[2\left(\gamma-90^{\circ}\right)\right.$ $\left.=2\left(93.262^{\circ}-90^{\circ}\right) \cong 6.5^{\circ}\right]$. Fig. $3.4 \mathrm{~b}$ shows two twin grids, which can be compared with the SAD pattern shown in Fig. 3.4a. Although these two twin components are related by $\mathrm{C}_{2}$ rotation along the crystallographic a axis as shown in Fig. $3.4 \mathrm{~b}$, the intensities of reflections from the two components are not equivalent because the twin operator is not the symmetry operator of $\beta-\mathrm{Gd}_{5} \mathrm{Si}_{2} \mathrm{Ge}_{2}$.

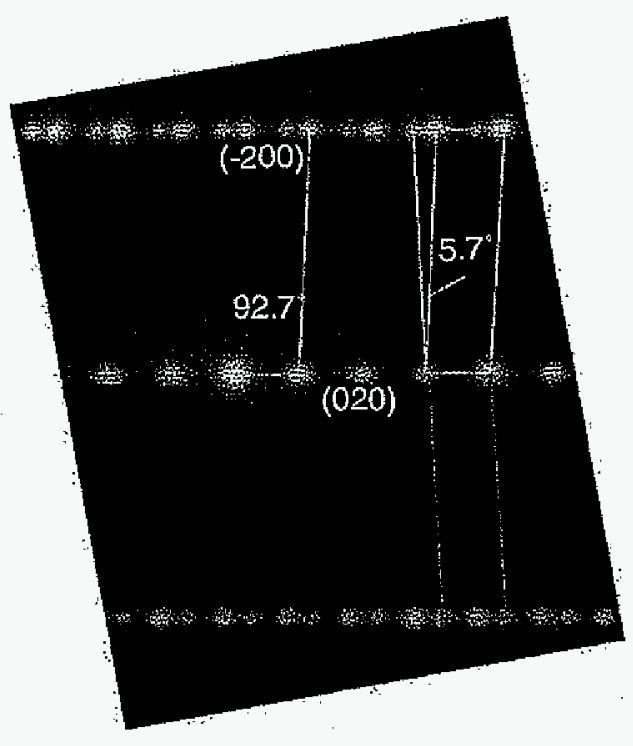

(a)

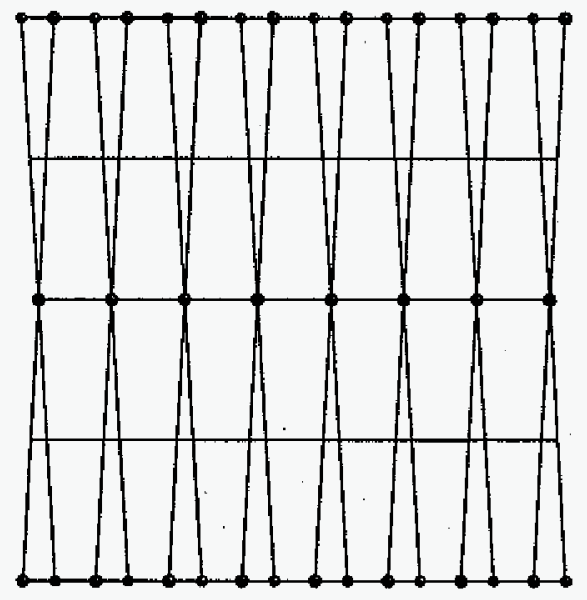

(b)

Figure 3.4. (a) $\mathrm{SAD}$ pattern for $\beta-\mathrm{Gd}_{5} \mathrm{Si}_{2} \mathrm{Ge}_{2}$ and (b) its corresponding twin grids. 

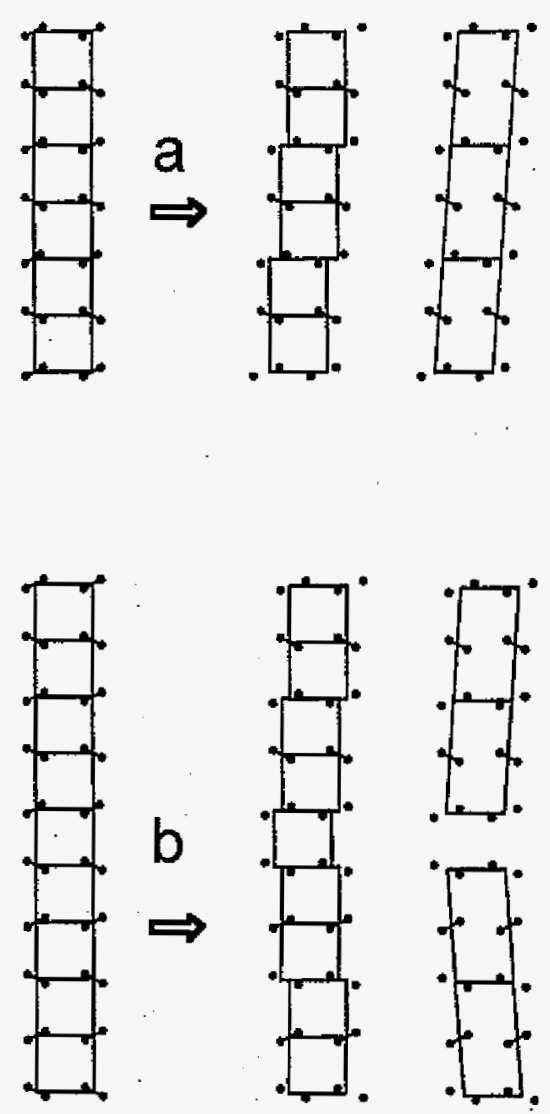

Figure 3.5. A possible model for the formation of twins during the $\alpha \rightarrow \beta$ phase transition caused by shear movement along the crystallographic [100] direction. The arrows indicate the movement of ${ }_{2}^{\infty}\left[G d_{5}\left(S i_{2} G e_{2}\right)\right]$ slabs, thereby breaking the dimers which connect adjacent ${ }_{2}^{\infty}\left[G d_{5}\left(S i_{2} G e_{2}\right)\right]$ slabs. If the shift movement involves pairs of slabs no twinning will occur (a), while twinning occurs when there is an occasional shear movement of just a single slab, thereby creating twinned monoclinic cells (b).

The shear movement of the ${ }_{2}^{\infty}\left[G d_{5}\left(S i_{2} G e_{2}\right)\right]$ slabs along the [100] axis is responsible not only for the $\alpha \rightarrow \beta$ phase transition, but also plays a crucial role for twin formation in $\beta-\mathrm{Gd}_{5} \mathrm{Si}_{2} \mathrm{Ge}_{2}$. Fig.3.5 illustrates a model for the formation of twin boundaries during the phase transition. If twinning is absent in the $\beta$-phase, alternate 
layers of $(\mathrm{Si}, \mathrm{Ge})-(\mathrm{Si}, \mathrm{Ge})$ dimers that bond two ${ }_{2}^{\infty}\left[G d_{5}\left(S i_{2} G e_{2}\right)\right]$ slabs together in the orthorhombic $\alpha$-phase along the [010] axis are broken as two adjacent slabs shift in opposite directions along the crystallographic [100] axis (see Fig. 3.5a). Twinning can be generated when two adjacent layers of $(\mathrm{Si}, \mathrm{Ge})$ dimers are broken at the same time. In this case a single ${ }_{2}^{\infty}\left[G d_{5}\left(\mathrm{Si}_{2} G e_{2}\right)\right]$ slab shifts with respect its neighboring slabs (see Fig. 3.5b) and two different orientations of monoclinic cells are identified, which are related to each other by $\mathrm{C}_{2}$ rotation along the [100] axis as mentioned previously. Consequently, nonmerohedral twinning occurs. One interesting feature of this model is that one false, irregular movement along the [100] axis can generate a twin. How often such irregular movement occurs determines whether the twin in $\beta-\mathrm{Gd}_{5} \mathrm{Si}_{2} \mathrm{Ge}_{2}$ is a macroscopic or a microscopic one. All attempts to isolate one of the two twin domains in the SAD pattern failed, suggesting that the nonmerohedral twin found in $\beta-\mathrm{Gd}_{5} \mathrm{Si}_{2} \mathrm{Ge}_{2}$ is more likely a microscopic one (i.e. the twin domain is smaller than the size area selected by the aperture). We also find that twinning in $\beta-\mathrm{Gd}_{5} \mathrm{Si}_{2} \mathrm{Ge}_{2}$ is intrinsic because we could not find any area in $\beta-\mathrm{Gd}_{5} \mathrm{Si}_{2} \mathrm{Ge}_{2}$ that was not twinned. It is possible that the apparent faults observed in the microstructure indicate some type of macroscopic twin. Since the movement needed to produce such a macroscopic twin as opposed to a microscopic one is identical, no apparent change in the SAD pattern would be observed. However, at this point this is simply speculation. 


\section{References}

1. (a) V. K. Pecharsky and K. A. Gschneidner, Jr., Phys. Rev. Lett. 78, 4494-4497 (1997); (b) V. K. Pecharsky and K. A. Gschneidner, Jr., Appl. Phys. Lett. 70, 3299-3301 (1997). (c) V. K. Pecharsky and K. A. Gschneidner, Jr., J. Magn. Magn. Mater. 167, L179-L184 (1997).

2. C. B. Zimm, Adv. Cryo. Eng. 43, 1759-1766 (1998).

3. V. K. Pecharsky and K. A. Gschneidner, Jr., J. Alloys Compd. 260, 98-106 (1997).

4. W. Choe, V. K. Pecharsky, A. O. Pecharsky, K. A. Gschneidner, V. G. Young Jr., and G. J. Miller, Phy. Rev. Lett. 84, 4617 (2000).

5. (a) V. V. Ivtchenko, V. K. Pecharsky, Gschneidner, Jr., Adv. Cryog. Eng. 46, 405 (2000). (b) Y. I. Spichkin, V. K. Pecharsky, Gschneidner, Jr., J. Appl. Phys. 89, 1738 (2001).

6. (a) R. Herbst-Irmer and G. M. Shelderick, Acta Cryst. B54, 443-449 (1998). (b) D. L. Reger, C. A. Little, V. G. Young, Jr., and M. Pink, Inorg. Chem. 40, 2870 (2001). (c) D. G. Colombo, V. G. Young, Jr., W. L. Gladfelter, Inorg. Chem. 39, 4621 (2000). (d) J. W. Schweitzer, L. S. Martinson, N. C. Baenziger, D. C. Swenson, V. G. Young, Jr., I. Guzei, Phys. Rev. B62, 12792 (2000).

7. J. S. Meyers, L. S. Chumbley, F. Laabs, and A. O. Pecharsky, Processing and Fabrication of Advanced Materials, $10^{\text {th }}$ Int'l Symposium (2001).

8. J. Szade, G. Skorek, and A. Winiarski, J. Cryst. Growth 205, 289-293 (1999). 


\section{Chapter 4. TEM Analysis}

The goal of this chapter is to report on the TEM analysis of $\mathrm{Gd}_{5} \mathrm{Si}_{2} \mathrm{Ge}_{2}$ and to expand upon the phase transition.

\section{Experimental Details:}

Transmission election microscopy (TEM) samples of $\mathrm{Gd}_{5} \mathrm{Si}_{2} \mathrm{Ge}_{2}$ were produced for examination from the arc-melted button examined at the end of Chapter 2 . The samples were mechanically thinned then reinforced with epoxy $353 \mathrm{ND}$ and a Mo support oval. Following reinforcement the sample was mechanically dimpled to a thickness of about $10 \mu \mathrm{m}$. During the dimpling process the samples were again reinforced with epoxy after cracks started to appear. After dimpling the samples were ion-milled until perforation. The ion-milling was initially carried out at room temperature until it was determined using TEM and electron diffraction that the ion-milling had caused the crystal structure to undergo the room temperature monoclinic to high temperature orthorhombic transition as discussed in Chapter 1. Subsequent samples ion-milled using a liquid nitrogen cooled stage were found to possess the proper room temperature monoclinic structure.

Samples were examined using a Philips CM30 S/TEM at room temperature and while being cooled through the transition using a Gatan 636 double tilt $\mathrm{LN}_{2}$ specimen holder. Bright field images (BF) and selected area diffraction (SAD) patterns were taken 
of the sample both off, and on, a number of zone axes. Convergent beam electron diffraction (CBED) was attempted but could not be used effectively to evaluate this material because the $\mathrm{b}$ axis was so large that it was impossible to obtain a pattern that did not have overlapping spots along the (010) plane even with the smallest condenser aperture.

\section{Experimental Results}

As stated in the previous section, initial samples for TEM observation were ionmilled at room temperature. TEM examination of these samples revealed two distinct structural features. A large-scale structure similar in appearance to twins was apparent at low magnification in many regions, Fig 4.1a, while a fine scale faulting was observed using high resolution electron microscopy (FIREM) on the (020) planes of the material,

Fig. 4.1b. SAD patterns confirmed that the material possessed the high temperature orthorhombic structure reported in [8], and these patterns with matching simulations are shown in Figure 4.2, while Table 4.1 contains the experimentally determined lattice information. 


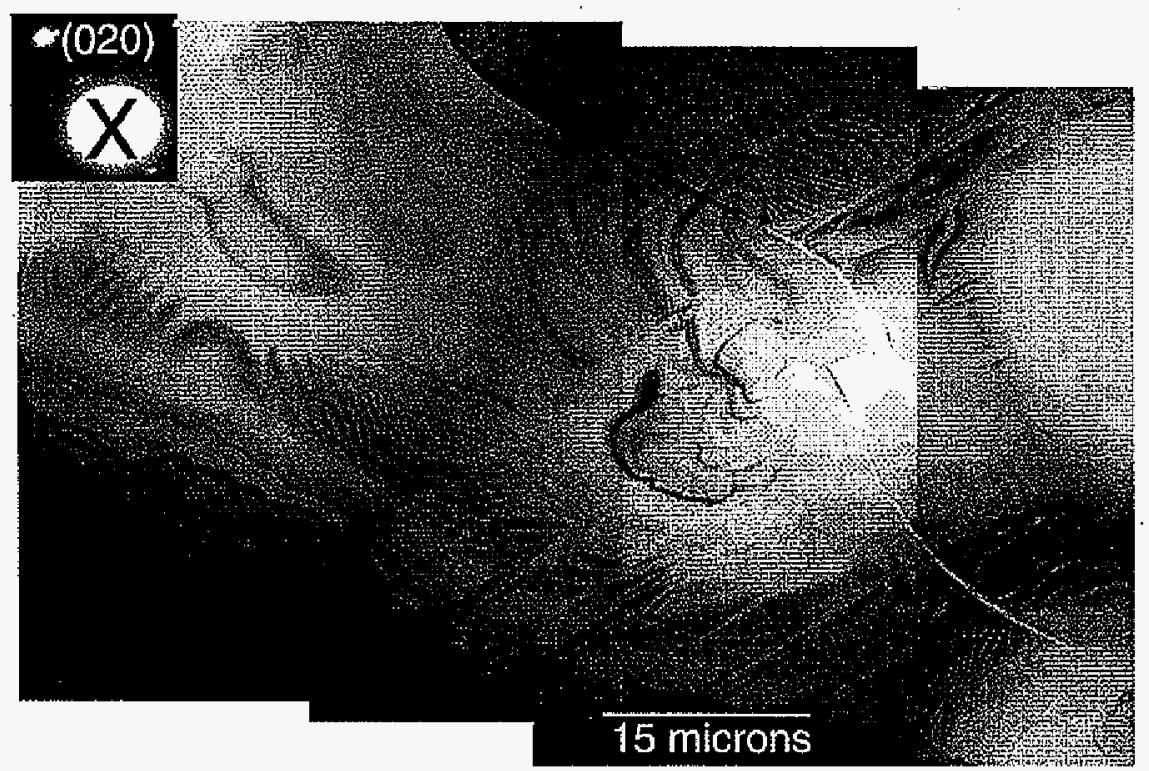

Figure 4.1a: BF image taken of the orthorhombic microstructure caused by room temperature ion milling. The apparent "twins" are visible on the (020).

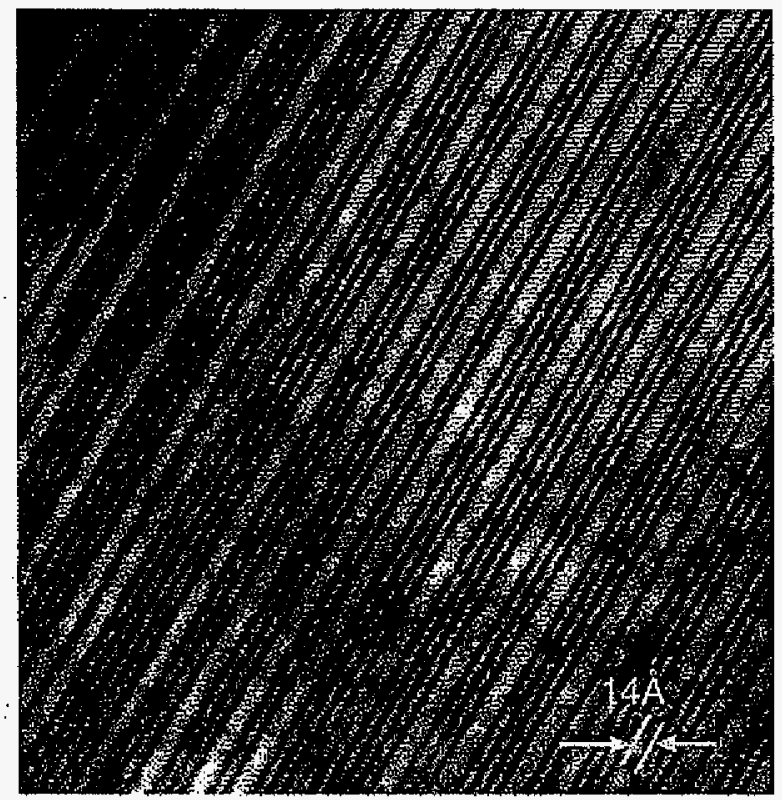

Figure 4.2b: HREM bright field image showing fine-scale faulting on (020) planes of the high temperature orthorhombic material. 


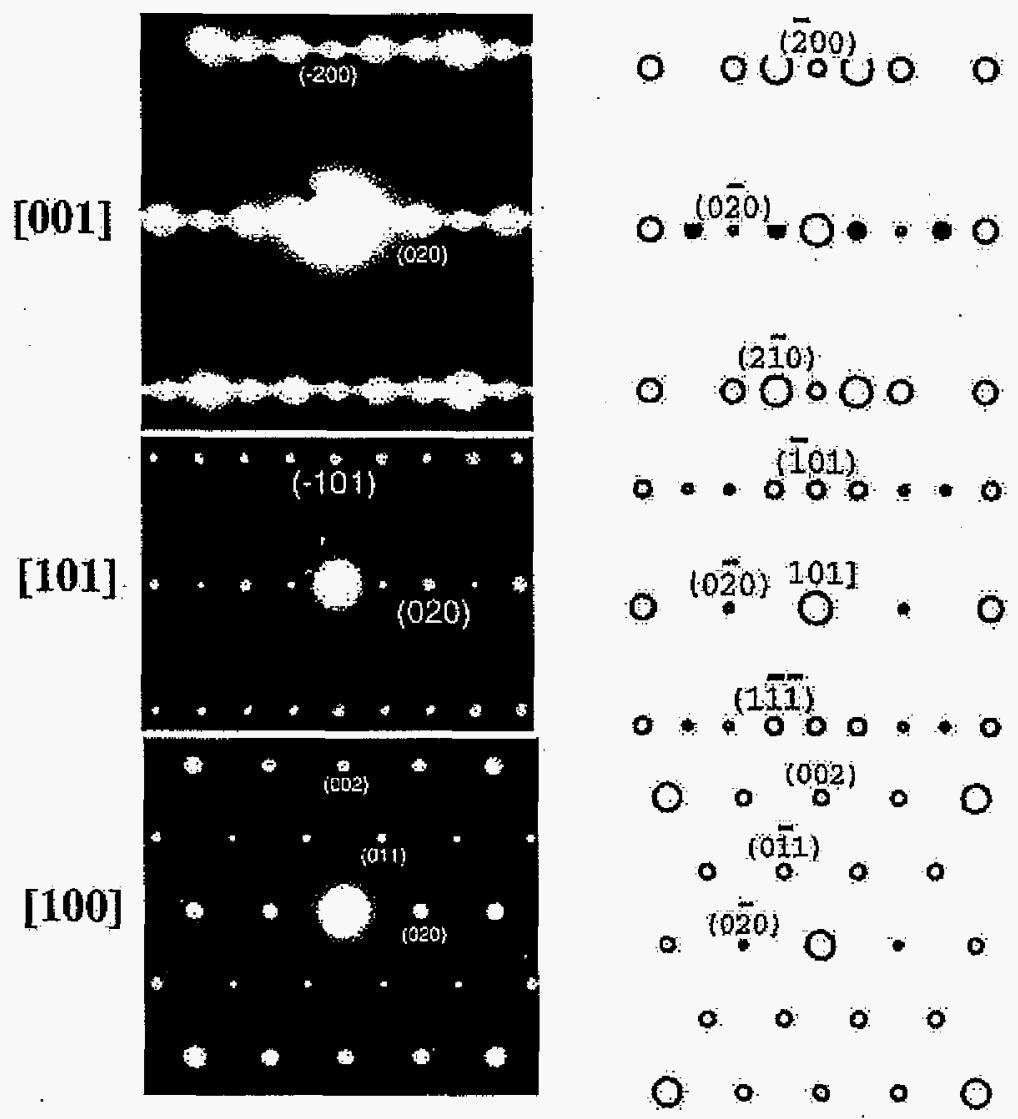

Figure 4.2. Confirmation of the orthorhombic crystal structure showing experimental SAD's, (left) and patterns simulated by Desktop Microscopist (right).

Table 4.1: Experimentally determined crystal information.

\begin{tabular}{|c|c|}
\hline Space Group: & Pnma \\
\hline a : & $7.56 \AA$ \\
\hline b : & $14.86 \AA$ \\
\hline $\mathrm{c}:$ & $7.74 \AA$ \\
\hline$\alpha:$ & $90^{\circ}$ \\
\hline$\beta$ & $90^{\circ}$ \\
\hline$\delta:$ & $90^{\circ}$ \\
\hline
\end{tabular}

What was interesting was that the apparent large-scale "twins" appeared to have no effect on the SAD patterns since SADs both on, off, and across the "twin" regions 
resulted in no discernable differences. While the fine-scale faults varied in spacing they were all too closely spaced to allow SADs to be obtained from an unfaulted region. It is also interesting to note from Figure 4.2 that streaking produced by the faults along the [020] direction when viewed near the (001) zone axis disappeared as the sample was tilted toward the [100].

Once it was determined that samples ion-milled at room temperature resulted in formation of the high temperature orthorhombic phase all subsequent samples were thinned using a $\mathrm{LN}_{2}$ cooled stage. A typical microstructure of one such sample is shown, Fig. 4.3. At low magnification the structure appears similar to the high temperature orthorhombic material, containing the same apparent large-scale "twins" as previously noted. However, the structure is monoclinic, as confirmed by the experimentally obtained lattice constants shown in Table 4.2 and the SAD patterns of Figure 4.4.

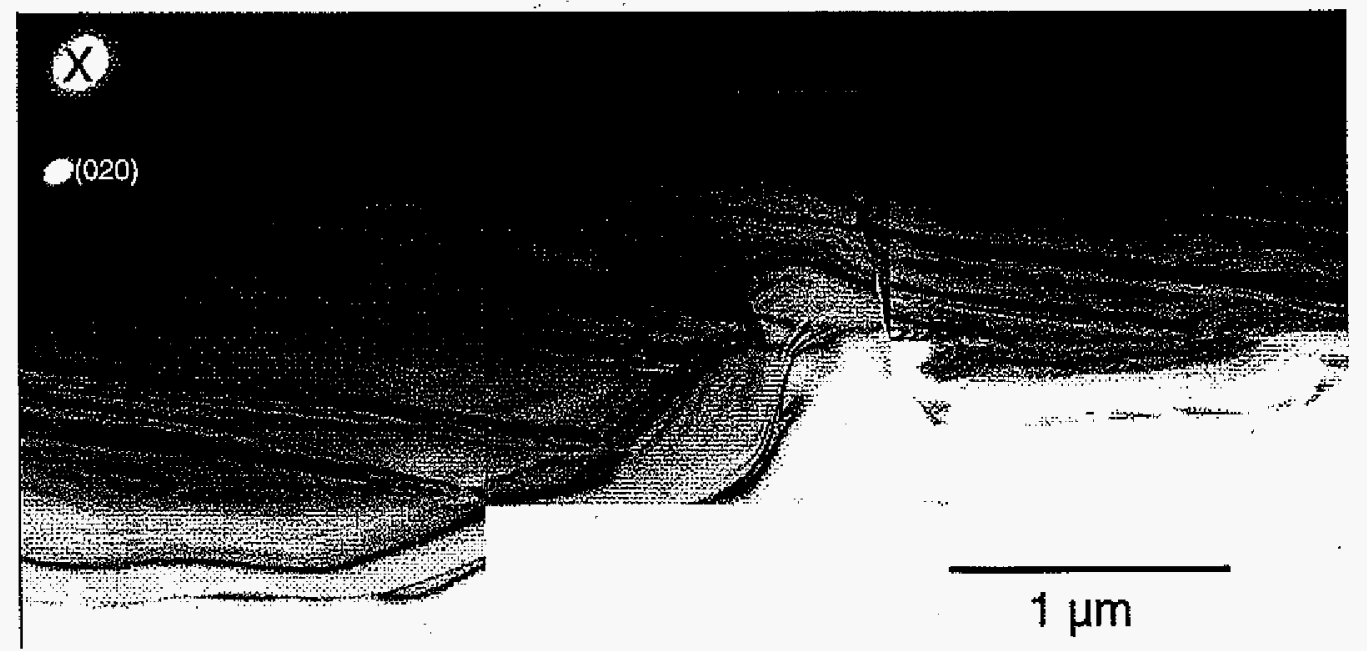

Figure 4.3. Bright field image of $\mathrm{Gd}_{5} \mathrm{Si}_{2} \mathrm{Ge}_{2}$ arc melted sample. Visible are "twins" that lay on the $(020)$ plane. 
Table 4.2: Crystal structure experimental results.

\begin{tabular}{|c|c|}
\hline Space Group: & P112/a \\
\hline $\mathrm{a}:$ & $7.60 \AA$ \\
\hline $\mathrm{b}:$ & $14.84 \AA$ \\
\hline $\mathrm{c}:$ & $7.82 \AA$ \\
\hline$\alpha:$ & $90^{\circ}$ \\
\hline$\beta$ & $90^{\circ}$ \\
\hline$\delta:$ & $92.7^{\circ}$ \\
\hline
\end{tabular}

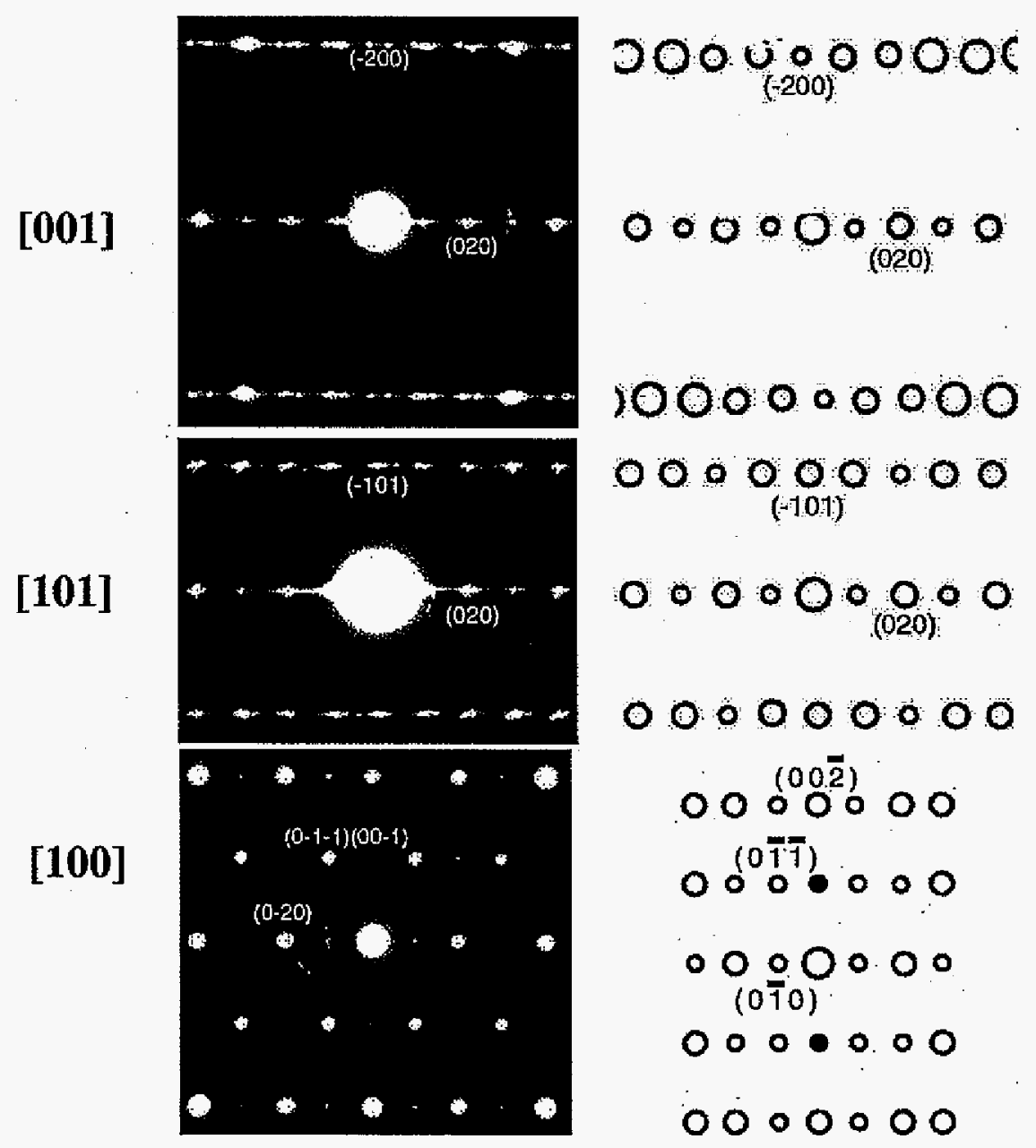

Figure 4.4. Confirmation of the crystal structure of the monoclinic material by compare the experimental SAD's, (left) to patterns simulated patterns (right). 
Note that extra reflections are present in the SAD patterns of Figure 4.4 due to the presence of twinning. The twin reflections have been discussed in Chapter 3 and are in agreement with the results of single crystal x-ray diffraction studies. A summary of the measured twin-related values are shown in Table 4.3.

Table 4.3: Data collected from the twin.

\begin{tabular}{|c|c|c|}
\hline Plane & Measured Spacing (XRD) & Measured Spacing (SAD) \\
\hline$(010)$ & $14.8 \AA$ & $14.84 \AA$ \\
\hline$(200)$ & $3.78 \AA$ & $3.80 \AA$ \\
\hline Measured angle between (100) and (012) & $92.7^{\circ}$ \\
\hline Measured angle of rotation caused by the twin & $5.7^{\circ}$ \\
\hline Plane on which the twin exists & $(020)$ \\
\hline
\end{tabular}

It should again be noted that the observed twinning in the SAD patterns is independent of the large-scale apparent "twins" observed within the sample. In other words, the twin reflections seen in Figure 4.4 are present whether the pattern was obtained within an area defined by the apparent "twins", outside of this area, or overlapping the two regions. This implies that the true twinning present in the samples occurs on an extremely fine scale, possibly on the order of a few atomic planes. Tilting the sample from [001] to [100] results in the disappearance of the twin reflections. This is consistent with previous $\mathrm{x}$-ray work [8] that has determined that the twins lie on the $\mathrm{a}, \mathrm{b}$ plane.

If viewed using the proper $\mathrm{g}$ such twinning might be expected to produce contrast similar to what was observed in the high temperature orthorhombic phase (Fig. 4.1b), 
where faulting was seen on this scale. High resolution imaging of the monoclinic structure along [100] and [001] directions are shown in Figure 4.5.

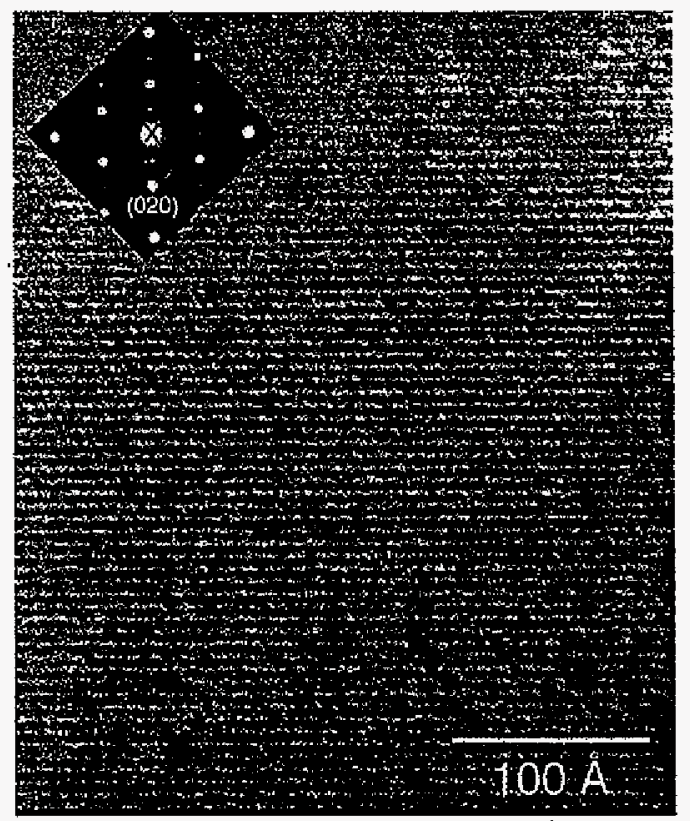

(a)

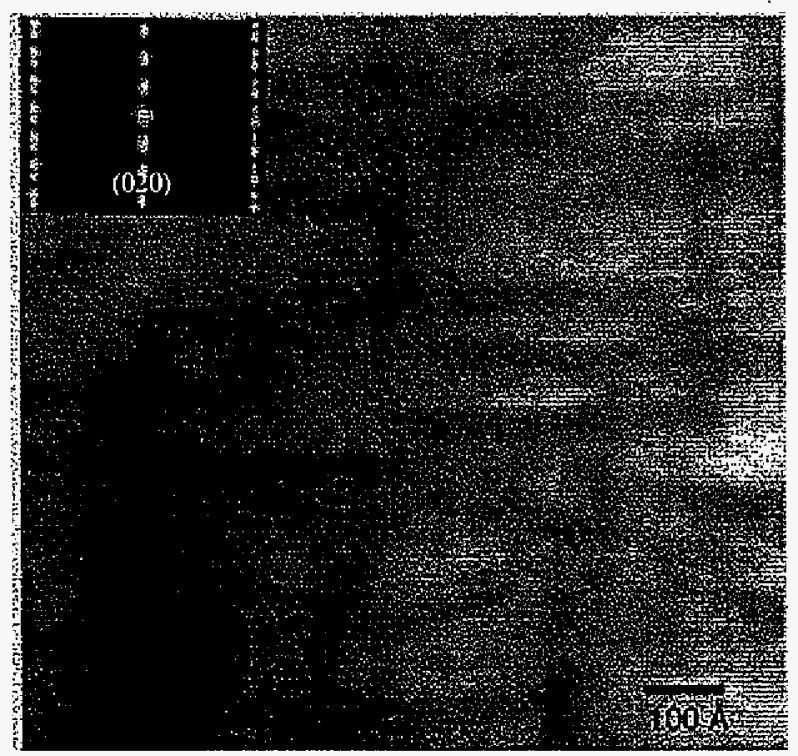

(b)

Figure 4.5. HREM bright field image showing lattice fringes on [100] (a) and lattice fringes and tweed structure on [001] (b).

When viewed along [100] the shift associated with the twin is not visible, since in this instance the movement associated with the twin lies along the [100] direction. Thus, imaging with $g=020$ along [100] reveals no such faulting, Fig 4.5a. However, using $g=$ 020 along the [001] direction produces a tweed-like contrast, Fig. 3.2 and Fig 4.5b. The appearance of the tweed-like structure corresponds with the presence of the twin reflections notes in Fig. 4.4, i.e. as the twin reflections disappear so does the tweed appearance of the microstructure. 


\section{Cold Stage Experiments}

Once the monoclinic structure was verified samples of $\mathrm{Gd}_{5} \mathrm{Si}_{2} \mathrm{Ge}_{2}$ were cooled below $0^{\circ} \mathrm{C}$, the phase transition temperature discussed in Chapter 1 . The results of this experiment are shown in Figure 4.6. The only change that could be visually observed was movement of the sample as it contracted from the phase transition, the dimensional changes also resulting in the propagation of an existing crack. No evidence of any nucleation of a new phase was evident, as might be expected if the transformation were a true martensitic phase transition. The structure appeared so similar that many of the bend contours present before the transformation appeared exactly the same afterwards.
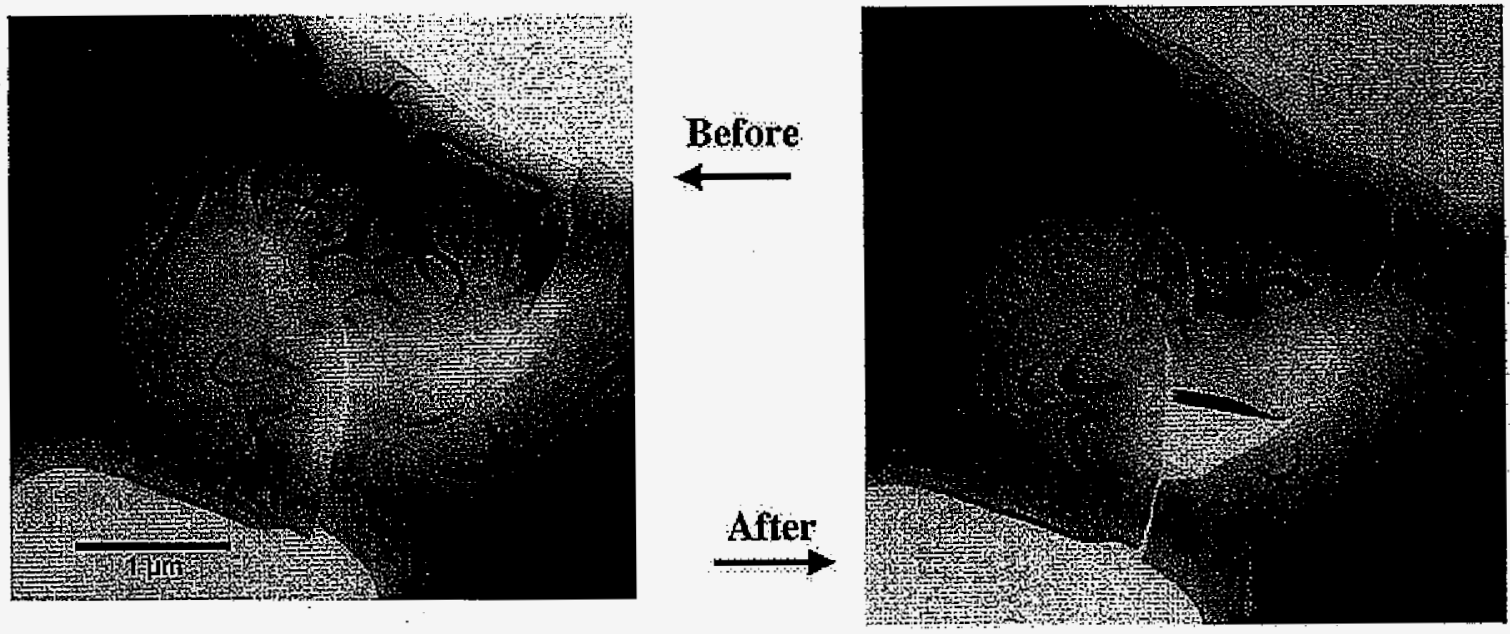

Figure 4.6. $\mathrm{BF}$ images taken before and after the phase transformation. Note the similar appearance of the bend contours and the propagation of the crack.

That the phase transformation has in fact occurred is confirmed by the SAD patterns of Figure 4.7, which shows the [103] zone axis both before and after the 
transformation. Note that the angle change from $93.4^{\circ}$ to $90^{\circ}$ is in agreement with what is expected. Also note that the transformation has resulted in the diffraction reflections being sharp and circular while before the transition they were oblong and diffuse, as is common with the twin related reflections indicating that the strain in the lattice has been relieved.

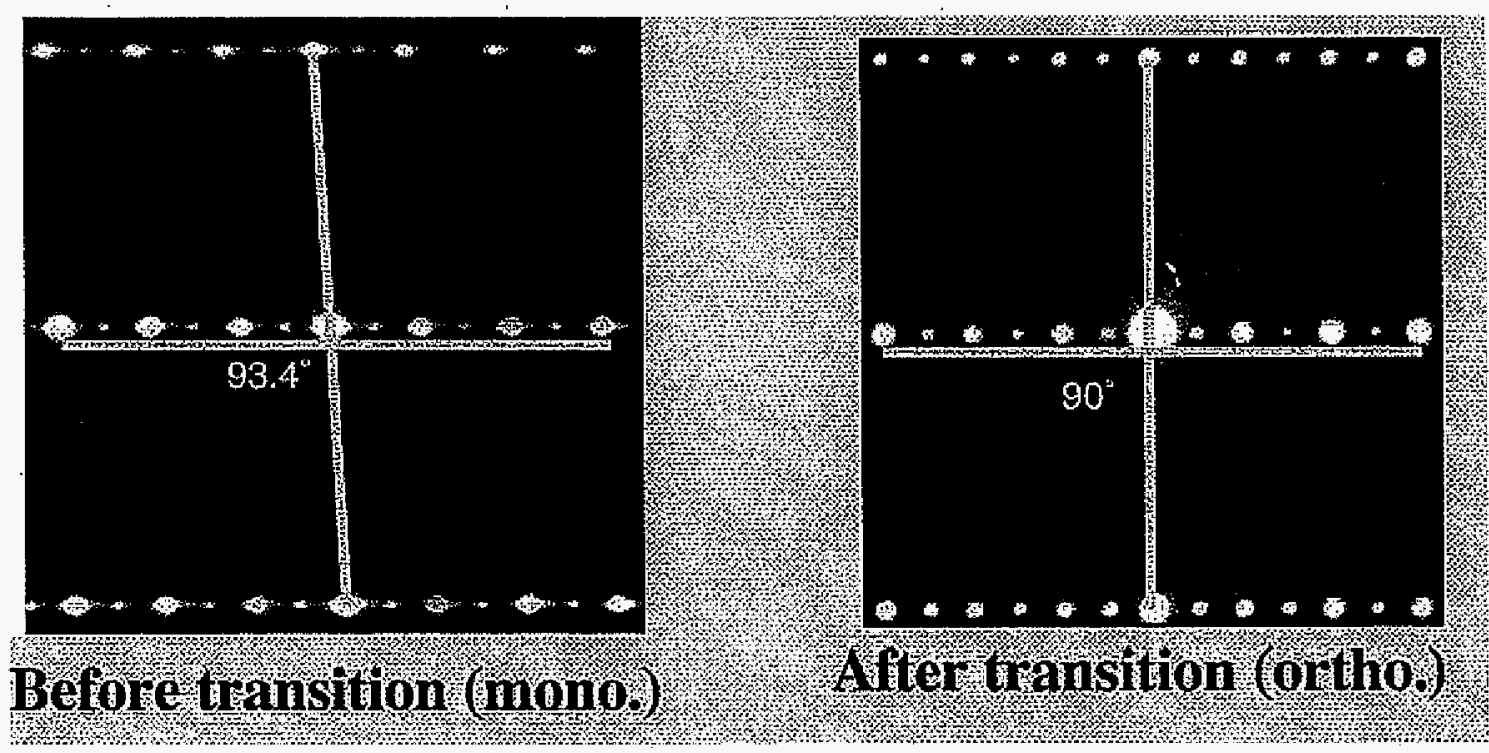

Figure 4.7. SAD taken of the [103] zone before, left, and after, right, the phase transformation.

The ferromagnetic nature of the structure was also apparent in the manner in which the electron beam was affected by the sample. While high resolution images of the paramagnetic monoclinic material could be obtained relatively easily it was impossible to image the atomic planes of the low temperature orthorhombic material. 
The high temperature orthorhombic material (produced by ion milling) was also examined briefly at low temperatures. In these experiments the electron transparent material was not seen to undergo any change at all, however, when cooled below the transition temperature the sample did affect the beam as would be expected for a ferromagnetic material. This would indicate that the high temperature orthorhombic material produced by ion milling has formed only in areas thin enough so as to be electron transparent.

\section{Discussion}

Examination of $\mathrm{Gd}_{5} \mathrm{Si}_{2} \mathrm{Ge}_{2}$ samples using TEM revealed that preparing samples using room temperature ion-milling causes the material to undergone an irreversible monoclinic-orthorhombic transition. This transition is usually only seen after heating $\mathrm{Gd}_{5} \mathrm{Si}_{2} \mathrm{Ge}_{2}$ monoclinic material to $200{ }^{\circ} \mathrm{C}$, indicating that substantial heating had occurred due to the milling process. Localized heating due to knock-on damage from the argon ions has been observed in other studies. When cooled to liquid nitrogen temperatures no change in structure was seen in the electron transparent regions but the sample had an obvious effect on the electron beam, indicating that the bulk of the sample had undergone the expected monoclinic-paramagnetic transition to orthorhombic-ferromagnetic. These observations support the conclusion that room temperature ion-milling has resulted in a change in the crystal structure in thin areas. 
Examination of the $\mathrm{Gd}_{5} \mathrm{Si}_{2} \mathrm{Ge}_{2}$ samples prepared using cold-stage ion milling revealed the expected monoclinic crystal structure. While what appeared to be obvious "twins" were present in bright-field images no evidence of these "twins" was observed in the SAD patterns. Instead, extra reflections accompanied by streaking in the patterns indicated that the material was heavily twinned on an extremely fine scale, in agreement with previous $\mathrm{x}$-ray studies. FREM imaging of the structure along [100] (the plane of the. twins, Fig 6a) using (020) revealed no faulting, while imaging along [001] (perpendicular to the twin plane) using (020) produced a tweed-like pattern. Similarly, SAD patterns taken along [100] shows distinct circular diffraction spots while patterns along [001] revealed streaking along the (020) plane, diffraction spots elliptical in shape, and twin spots. These results were analogous to what was observed in the high temperature orthorhombic material, where when imaging faults were seen and in diffraction streaking was seen when the beam direction was along [001]. 


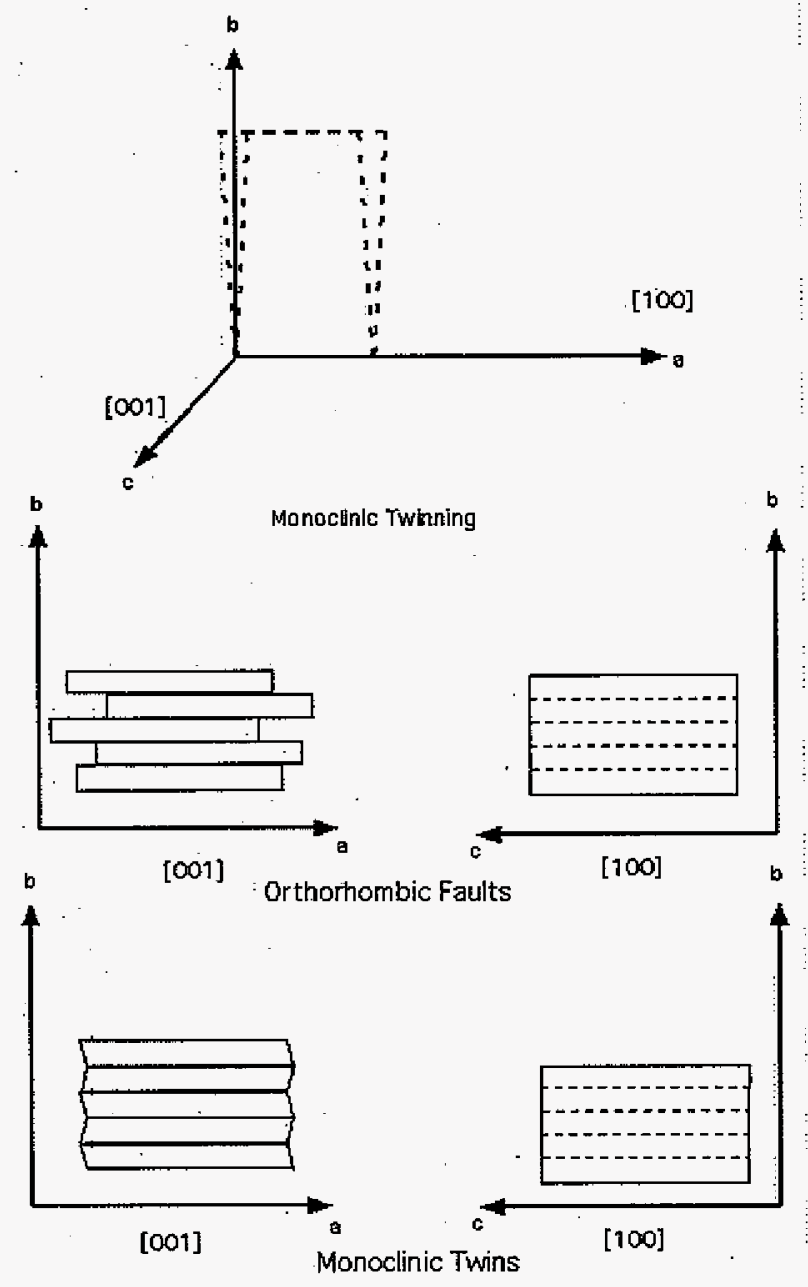

Figure 4.8. Schematic of how the twins and faults would be viewed in the TEM from different zones since the displacement in both instances is along the a axis, observation along the [100] fails to reveal the faults / twins.

The images and streaking seen in both the high temperature orthorhombic and monoclinic materials may be explained by a consideration of Figure 4.8, which schematically shows how the crystal structure is distorted by the orthorhombic / monoclinic phase transition. Twinning takes place in the $a-b$ plane of this material producing a displacement in the monoclinic material along the a axis. When the a-b 
plane is viewed along [001] (perpendicular to the twin plane) the twinned regions will appear to act as thin crystals, distorted to accommodate the stress associated with the twin. The maximum displacement of the lattice is seen in this direction and, therefore, a significant amount of residual stress may be expected. The diagram accounts for the tweed structure and the streaking observed in SAD patterns. As the viewing direction moves from [001] to [100] the projected displacement of the planes associated with the twin becomes less, such that when viewed along [100] the displacement is entirely contained within the viewing direction. Images taken along this direction appear regular with no diffraction streaking observed.

At high temperature the material relieves the stress caused by twinning in the monoclinic structure by undergoing a phase change to orthorhombic. The twinned material shifts slightly, resulting in an orthorhombic structure where the twinned regions now appear as thin faults when viewed along [001] (Fig. 4.1b). Some streaking still remains, although now it associated with the thin nature of the faults and less with strain in the lattice.

This explanation is also consistent with the manner in which the streaking observed in the diffraction patterns changes as the viewing direction changes from [001] to [100]. For the monoclinic phase considerable streaking is still evident in the SAD patterns of the [101] zone axis (Fig. 4.4). This is not the case for the orthorhombic phase 
where the streaking has essentially disappeared in the [101] pattern. Similarly, the amount of streaking present in the samples decreases after the material has undergone the monoclinic - orthorhombic transition at low temperatures. This is illustrated in Figure 4.7 which shows that the extensive streaking present in the monoclinic material on the [103] zone axis has disappeared from the same axis in the orthorhombic material.

Observation of the low temperature monoclinic - orthorhombic transition revealed that previous description of the transformation as a "magnetic-martensitic" [12] transition technically is not correct. A martensitic transformation involves nucleation and growth of a martensitic phase, within a parent phase [27]. Imaging of the $\mathrm{Gd}_{5} \mathrm{Si}_{2} \mathrm{Ge}_{2}$ Iow temperature phase transition showed no sign of nucleation or growth of a second phase. While SAD patterns confirmed that the transformation had occurred the orientation relationship that existed between the two phases showed perfect matching of the structures along crystallographic directions. Such alignment is often not the case in martensitic transformations.

The phase transition can best be described as a diffusionless, displacive transformation known as a ferroelastic phase transformation. The author of [28] defines a ferroic material as "...one which can, or can be conceived to, undergo one or more ferroic phase transitions ... ferroelastic crystals are those which undergo, or can be deemed to have undergone at least one ferroelastic phase transition." Other authors state 
that a ferroic phase transition involves a change in point-group symmetry [29] that is achieved by lowering the crystal's symmetry to a second space group that is a subgroup of the first space group [30]. Thus, a ferroelastic phase transition is defined as a ferroic phase transition that involves a change in crystal system [28]. Chapter 1 has shown that $\mathrm{Gd}_{5} \mathrm{Si}_{2} \mathrm{Ge}_{2}$ meets these qualifications since the monoclinic phase (space group P112/a) which belongs to point group $2 / \mathrm{m}$, is a subgroup of Pnma, that belongs to point group mmm.

Classically ferroic materials have been defined as materials that show hysteresis behavior in the material's electric, magnetic or elastic properties and $\mathrm{Gd}_{5} \mathrm{Si}_{2} \mathrm{Ge}_{2}$ has already been shown to be ferromagnetic in its orthorhombic phase. $\mathrm{Gd}_{5} \mathrm{Si}_{2} \mathrm{Ge}_{2}$ also transforms from monoclinic-twinned, to orthorhombic-untwinned by the ferroic phase transition. It would appear that this is the reverse of what is normally seen in ferroic materials, i.e. an ordered low-symmetry phase typically transforms to a disordered highsymmetry phase. However, if one considers the definition of a ferroelastic material provided by [28] the monoclinic phase can be considered as being ferroelastic. Thus, the phase transformation can be viewed as a ferroic phase transition where a ferroelastic. material transforms to a ferromagnetic material. This type of coupling between different classes of ferroic behavior has been noted in other systems [31]. Therefore, $\mathrm{Gd}_{5} \mathrm{Si}_{2} \mathrm{Ge}_{2}$ 
may be both ferromagnetic in the orthorhombic phase and ferroelastic in the monoclinic

phase.

Measurement of $\mathrm{Gd}_{5} \mathrm{Si}_{2} \mathrm{Ge}_{2}$ 's mechanical properties through use of a simple tensile test would be the classical way to determine if the material truly were ferroelastic.

This method most likely will not work because of the material's intrinsic tendency to crack, preventing a true test of the elastic properties from being performed. However, describing monoclinic $\mathrm{Gd}_{5} \mathrm{Si}_{2} \mathrm{Ge}_{2}$ as ferroelastic explains the presence of the twins and the large amount of internal stress observed in SAD patterns of the disordered state.

If the material is indeed ferroelastic in nature, tables from [29] can be used to predict on which planes the spontaneous strain, an intrinsic property of a ferroelastic phase, will occur (Fig. 4.9a), and the equations from [29] can be applied to calculate the entire spontaneous strain tensor. The tables predict that for a ferroelastic phase transition from orthorhombic mmm to monoclinic $2 / \mathrm{m}$ the strain tensor will be zero except for two shear stresses that are symmetric with respect to each other. 


\begin{tabular}{|c|cc|c|c|c|}
\hline Point Group & Subgroup & $\begin{array}{c}\text { Active } \\
\text { Rep. }\end{array}$ & $\begin{array}{c}\text { Spontaneous } \\
\text { Strain Generated }\end{array}$ & $\begin{array}{c}\text { Elastic } \\
\text { Domains }\end{array}$ \\
\hline 222 & 2 & $\mathrm{c}$ & $\mathrm{B}_{1}$ & $2 * \mathrm{e}_{12}$ & 2 \\
\hline 222 & 2 & $\mathrm{c}$ & $\mathrm{B}_{2}$ & $2 * \mathrm{e}_{13}$ & 2 \\
\hline 222 & 2 & $\mathrm{c}$ & $\mathrm{B}_{3}$ & $2 * \mathrm{e}_{23}$ & 2 \\
\hline $\mathrm{mm} 2$ & 2 & $\mathrm{c}$ & $\mathrm{A}_{2}$ & $2 * \mathrm{e}_{12}$ & 2 \\
\hline $\mathrm{mm} 2$ & $\mathrm{~m}$ & $\mathrm{c}$ & $\mathrm{B}_{1}$ & $2 * \mathrm{e}_{13}$ & 2 \\
\hline $\mathrm{mm} 2$ & $\mathrm{~m}$ & $\mathrm{c}$ & $\mathrm{B}_{2}$ & $2 * \mathrm{e}_{23}$ & 2 \\
\hline $\mathrm{mmm}$ & 222 & $\mathrm{c}$ & $\mathrm{A}_{\mathrm{u}}$ & none & 1 \\
\hline $\mathrm{mmm}$ & $2 / \mathrm{m}$ & $\mathrm{c}$ & $\mathrm{B}_{\mathrm{lg}}$ & $2 * \mathrm{e}_{12}$ & 2 \\
\hline $\mathrm{mmm}$ & $2 / \mathrm{m}$ & $\mathrm{c}$ & $\mathrm{B}_{2 \mathrm{~g}}$ & $2 * \mathrm{e}_{13}$ & 2 \\
\hline $\mathrm{mmm}$ & $2 / \mathrm{m}$ & $\mathrm{c}$ & $\mathrm{B}_{3 \mathrm{~g}}$ & $2 * \mathrm{e}_{23}$ & 2 \\
\hline $\mathrm{mmm}$ & $\mathrm{mm} 2$ & $\mathrm{c}$ & $\mathrm{B}_{\mathrm{ll}}$ & none & 1 \\
\hline $\mathrm{mmm}$ & $\mathrm{mm} 2$ & $\mathrm{c}$ & $\mathrm{B}_{2 \mathrm{u}}$ & none & 1 \\
\hline $\mathrm{mmm}$ & $\mathrm{mm} 2$ & $\mathrm{c}$ & $\mathrm{B}_{3 \mathrm{u}}$ & none & 1 \\
\hline
\end{tabular}

(a)

$$
\begin{aligned}
& e_{11}-\frac{\sin \gamma}{a_{0} \sin \gamma} 1 \\
& e_{22}=\frac{\mathrm{b}}{\mathrm{b}_{\mathrm{o}}} \mathrm{a} \\
& e_{\beta j}=\frac{c \sin \alpha \sin \beta_{0}}{\theta_{o} \sin \alpha_{b} \sin \beta_{0}^{2}}-1 \\
& e_{12}=\frac{1}{2}\left(\frac{a \cos \gamma}{a_{0} \sin \gamma_{0}}-\frac{b c o s \gamma_{0}}{b_{0} \sin \gamma_{0}}\right)
\end{aligned}
$$

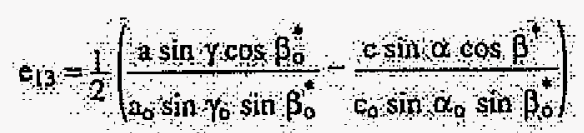

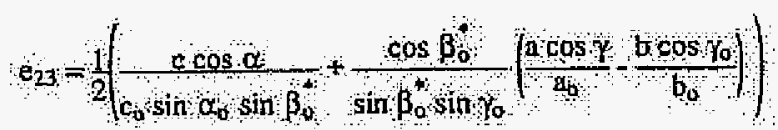

$$
\begin{aligned}
& \frac{b c o s \alpha_{0}}{b \sin \alpha_{0} \sin \beta_{0}}
\end{aligned}
$$

Figure 4.9. Tables, and Equations from [29] for determining spontaneous strain in ferroelastic materials. (a) is a table showing the spontaneous strain associated with different ferroelastic phase transformations. (b) contains the equations to calculate the spontaneous strain tensor. 
The strain tensor (Fig. 4.10) calculated with orthorhombic as the original phase $\left(a_{0}, b_{0}, c_{0}\right.$, etc. $)$ and monoclinic phase as the second phase $(a, b, c$, etc. $)$ reveals that the only significant strains are $e_{12}$ and $e_{21}$, which have to be symmetrical. In other words, the strain occurs on the $a-b$ plane. This is in agreement with what has been observed by SAD since, as discussed earlier, SAD of the [001], or a-b plane, shows large amounts of strain while SAD of the [100], or b-c plane, does not show any sign of strain.

$$
e_{i j}=\left[\begin{array}{ccc}
8.47 * 10^{-3} & -.029 & 0 \\
-.029 & 2.03 * 10^{-3} & 0 \\
0 & 0 & -1.03 * 10^{-3}
\end{array}\right]
$$

Figure 4.10. Strain tensor caused by the ferroelastic phase transition using equations from [29].

The obvious "twins" seen at all temperatures and in all phases (i.e. high and low orthorhombic phases, monoclinic phase) that exhibit no noticeable diffraction effects have yet to be explained. It is possible that these "twins" are thin planar layers along which either composition variations exist or where the microscopic twins noted in the monoclinic material form a macroscopic twin of as yet unknown orientation. Further work needs to be carried out to elucidate the crystallographic nature of these features. 


\section{Summary and Conclusions}

The TEM analysis of $\mathrm{Gd}_{5} \mathrm{Si}_{2} \mathrm{Ge}_{2}$ has:

1) Confirmed the monoclinic room temperature crystal structure determined by $x$-ray diffraction.

2) Shown that ion-milling of the thin film transfers enough energy to the system to cause the material to undergo a high temperature irreversible phase transition from monoclinic to orthorhombic.

3) Illustrated that the room temperature monoclinic phase is twinned with a considerable amount of residual stress that is relieved by the low temperature phase change.

4) Illustrated that the transition is, in fact, displacive and diffusionless but not martensitic in nature and is best described as a ferroelastic phase transition.

5) Shown that a structure similar in appearance to a twin but giving rise to no noticeable diffraction effects exists at all temperatures and in all phases. The exact nature of this structure remains a mystery at this time. 


\section{References}

[1] Smith, Gordon S., A.G. Tharp and Quintin Johnson, "Rare earth-germanium and -silicon compound at 5:4 and 5:3 compositions", Acta Crystallography 22, pp: 940-943 (1967).

[2] F. Holtzberg, R.J. Gambino, T.R. McGuire, "New Ferromagnetic 5:4 Compounds in the Rare Earth Silicon and Germanium System", Jounral of Physics and Chemistry of Solids 28, pp. 2283-2289 (1967).

[3] V.K. Pecharsky, K.A. Gschneidner Jr., "Giant Magnetocaloric Effect in $\mathrm{Gd}_{5}\left(\mathrm{Si}_{2} \mathrm{Ge}_{2}\right)$," Physical Review Letters 78(23), pp. 4494-4497 (1997).

[4] Pecharsky, Vitalij K. Karl A. Gschneidner, "Tunable magnetic regenerator alloys with a giant magnetocaloric effect for magnetic refrigerator from $\approx 20$ to $\approx 290^{\circ}$ K.", Applied Physics Letter 70(24), pp:3299-3301 (1997),.

[5] V.K. Pecharsky, K.A. Gschneidner Jr., "Phase Relationships and Crystallography in the Pseudobinary System $\mathrm{Gd}_{5} \mathrm{Si}_{4}-\mathrm{Gd}_{5} \mathrm{Ge}_{4}$.", Journal of Alloys and Compounds 260, pp: 98-106 (1997).

[6] L. Morellon, P. A. Algarabel, M. R. Ibarra, J. Blasco and B. Garcia-Landa, "Magnetic-field-induced structural phase transition in $\mathrm{Gd}_{5} \mathrm{Si}_{1.8} \mathrm{Ge}_{2.2}$. Physical Review B 58(22), pp: R14 721 - R14 724 (1998).

[7] L. Morellon, P. A. Algarabel, C. Magen, and M. R. Ibarra, "Giant magnetoresistance in the Ge-rich magnetocaloric compound $\mathrm{Gd}_{5}\left(\mathrm{Si}_{0.1} \mathrm{Ge}_{0.9}\right)_{4}$," Applied Physics Letter 73 (23), pp: $3462-3464$ (1998).

[8] W. Choe, V. K. Pecharsky, A. O. Pecharsky, K. A. Gschneidner, V. G. Young Jr., G. J. Miller, "Making and Braking Covalent Bonds across the Magnetic Transitionin the Giant Magnetocaloric Material $\mathrm{Gd}_{5}\left(\mathrm{Si}_{2} \mathrm{Ge}_{2}\right)$ ", Physical Review Letters 84(20), pp: 4617-4620 (2000).

[9] V. K. Pecharsky, A. O. Pecharsky and K. A. Gschneidner Jr, "Uncovering the structure-property relationships in $\mathrm{R}_{5}\left(\mathrm{Si}_{\mathrm{x}} \mathrm{Ge}_{4 \mathrm{x}}\right)$ intermetallic phase." Accepted for publication by: JALCOM; (2002). 
[10] J. Szade, G. Skorek, "Electronic Structure and Magnetism of $\mathrm{Gd}_{5}(\mathrm{Si}, \mathrm{Ge})_{4}$ compounds", Journal of Magnetism and Magnetic Materials, pp: 196-197, 699700 (1999).

[11] J. Szade, G. Skorek, A. Winiarski, "Surface Structure of $\mathrm{Gd}_{5}(\mathrm{Si}, \mathrm{Ge})_{4}$ crystals", Journal of Crystal Growth 205(3), pp:289-293 (1999).

[12] V. K. Pecharsky, K. A. Gschneidner Jr., " $\mathrm{Gd}_{5}\left(\mathrm{Si}_{x} \mathrm{Ge}_{1-x}\right)_{4}$ : An Extremum Material”, Advanced Materials 13(9) (2001), pp: 683-686.

[13] G. H. Rao, "Correlation between crystal structure and magnetic properties of $\mathrm{Gd}_{5}\left(\mathrm{Si}_{x} \mathrm{Ge}_{1-\mathrm{x}}\right)_{4}$ compounds", Journal of Physics: Condensed Matter, (2000), 12(6), pp: L93-L99.

[14] V. K. Pecharsky, K. A. Gschneidner Jr., "Effect of alloying on the giant magnetocaloric effect of $\mathrm{Gd}_{5} \mathrm{Si}_{2} \mathrm{Ge}_{2}$ ", Journal of Magnetism and Magnetic Material, (1997), 167(3), pp: L179-L184.

[15] A. Giguere, M. Foldeaki, B. Ravi Gopal, R. Chahine, T. K. Bose, A. Frydman, J. A. Barclay, "Direct Measurement of the 'Giant' Adiabatic Temperature Change in $\mathrm{Gd}_{5} \mathrm{Si}_{2} \mathrm{Ge}_{2}$ ", Physics Review Letter, (1999), 83(11), pp: 2262-2265.

[16] V. K. Pecharsky, L. Bruck, H. G. M. Duijn, E. M. Levin, "Comment on 'Direct measurement of the 'giant' adiabatic temperature change in $\mathrm{Gd}_{5} \mathrm{Si}_{2} \mathrm{Ge}_{2}$ "', Physical Review Letters, (2000), 85(19), p:4190.

[17] J. R. Sun, F. X. Hu, B. G. Shen, "Comment on 'Direct measurement of the 'giant' adiabatic temperate temperature change in $\mathrm{Gd}_{5} \mathrm{Si}_{2} \mathrm{Ge}_{2}$ "', Physical Review Letters, (2000), 85(19), p:4191.

[18] M. Foldeaki, R. Chahine, T. K. Bose, J. A. Barclay, "Reply to comment on 'Direct measurement of the 'giant' adiabatic temperate temperature change in $\mathrm{Gd}_{5} \mathrm{Si}_{2} \mathrm{Ge}_{2}$ "', Physical Review Letters, (2000), 85(19), p:4192.

[19] V. K. Pecharsky, K. A. Gschneidner Jr., "Magnetocaloric effect and magnetic refrigeration.", Journal of Magnetic Material, (1999), . 200(1-3), pp: 44-56.

[20] V. K. Pecharsky, K. A. Gschneidner Jr., "Magnetocaloric materials", Annual Review of Materials Science, (2000), 30, pp: 387-429. 
[21] V. K. Pecharsky, K. A. Gschneidner Jr., A. O. Pecharsky, A. M. Tishin, "Thermodynamics of the magnetocaloric effect", Physical Review B: Condensed Matter Physics, (2001), 64, pp: 144406-1-144403-13.

[22] L. Morellon, J. Blasco, P. A. Algarabel, M. R. Ibarra, "Nature of the first-order antiferromagnetic-ferromagnetic transition in Ge-rich magnetocaloric compounds $\mathrm{Gd}_{5}\left(\mathrm{Si}_{\mathrm{x}} \mathrm{Ge}_{\mathrm{I}-\mathrm{x}}\right)_{4}$ ". Physical Review B: Condensed Matter Physics, (1998), 62(2), pp: R1022 - 1026 .

[23] E. M. Levin, V. K. Pecharsky, K. A. Gschneidner Jr., "Magnetic-field and temperature dependencies of the electrical resistance near the magnetic and crystallographic first-order phase transition of $\mathrm{Gd}_{5} \mathrm{Si}_{2} \mathrm{Ge}_{2}{ }^{\text {"3 }}$, Physics Review $B$ : Condensed Matter Physics, (1999), 60(11), pp: 7993-7997.

[24] E. M. Levin, V. K. Pecharsky, K. A. Gschneidner Jr., P. Tomlinson, "Magnetic field and temperature-induced first-order transition in $\mathrm{Gd}_{5}\left(\mathrm{Si}_{1.5} \mathrm{Ge}_{2.5}\right)$ : a study of the electrical resistance behavior", Journal of Magnetism and Magnetic Materials, (2000), 210(1-3), pp: 181-188.

[25] L. Morellon, P. A. Algarabel, C. Magen, M. R. Ibarra, "Gaint magnetoresistance in the Ge-rich magnetocaloric compound, $\mathrm{Gd}_{5}\left(\mathrm{Si}_{0.1} \mathrm{Ge}_{0.9}\right)_{4}$ " Journal of Magnetism and Magnetic Materials, (2001), 237, pp: 119-123.

[26] K. A. Gschneidner Jr., V. K. Pecharsky, A. O. Pecharsky, T. A. Lograsso, D. L. Schlagel, "Production of the Giant Magnetocaloric Effect $\mathrm{Gd}_{5}\left(\mathrm{Si}_{\mathrm{x}} \mathrm{Ge}_{1-\mathrm{x}}\right)_{4}$ Magnetic Refrigeration Materials from Commercial Gadolinium Metal", Rare Earths and Actinides: Science, Technology and Applications $I V$, Proceedings Symposium (2000), pp:63-72.

[27] John D. Verhoeven, Fundamentals of Physical Metallurgy, New York: Wiley, 1975.

[28] V. K. Wadhawan, Introduction to Ferroic Materials, Gordon and Breach Science Publishers, 2000.

[29] Ekhard K. H. Salje, Phase Transitions in Ferroelastic and Co-Elastic Crystals, New York: Cambridge UP, 1993.

[30] W. Schranz, "Domains and interfaces near ferroic phase transitions", Key Engineering Materials, (1995), Vol. 101-102, pp: 41-60. 
[31] M. E. Lines and A. M. Glass, Principles and Applications of Ferroelectrics and Related Materials, Oxford: Clarendon Press, 1977. 


\section{Acknowledgments}

This work was preformed at Ames Laboratory under Contract No. W-7405-Eng-82 with the U.S. Department of Energy. The United States government has assigned the DOE Report number IS-T 1927 to this thesis. Also I would like to thank my committee members, Fran Laabs, Mathew Kramer, Wonyoung Choe and many others for their patience answering my many questions. 